Article

\title{
Nonlinear Characteristics of NPP Based on Ensemble Empirical Mode Decomposition from 1982 to 2015-A Case Study of Six Coastal Provinces in Southeast China
}

\author{
Peng Xue 1,2,3,4,5 ${ }^{(D}$, Huiyu Liu 1,2,3,4,5,*(D), Mingyang Zhang ${ }^{6,7} \mathbb{D}$, Haibo Gong ${ }^{1,2,3,4,5}$ and Li Cao ${ }^{1,2,3,4,5}$ \\ 1 Jiangsu Center for Collaborative Innovation in Geographical Information Resource Development and \\ Application, Nanjing Normal University, Nanjing 210023, China; 201302001@njnu.edu.cn (P.X.);

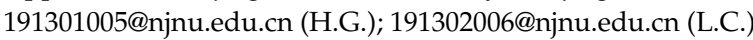 \\ 2 Key Laboratory of Virtual Geographic Environment, Nanjing Normal University, Ministry of Education, \\ Nanjing 210023, China \\ 3 State Key Laboratory Cultivation Base of Geographical Environment Evolution (Jiangsu Province), \\ Nanjing Normal University, Nanjing 210023, China \\ 4 College of Geography Science, Nanjing Normal University, Nanjing 210023, China \\ 5 Jiangsu Key Laboratory of Environmental Change and Ecological Construction, Nanjing Normal University, \\ Nanjing 210023, China \\ 6 Key Laboratory of Agro-Ecological Processes in Subtropical Region, Institute of Subtropical Agriculture, \\ Chinese Academy of Sciences, Changsha 410125, China; zhangmingyang@isa.ac.cn \\ 7 Huanjiang Observation and Research Station for Karst Ecosystems, Chinese Academy of Sciences, \\ Huanjiang, Hechi 547100, China \\ * Correspondence: liuhuiyu@njnu.edu.cn
}

check for updates

Citation: Xue, P.; Liu, H.; Zhang, M.; Gong, H.; Cao, L. Nonlinear Characteristics of NPP Based on Ensemble Empirical Mode Decomposition from 1982 to 2015-A Case Study of Six Coastal Provinces in Southeast China. Remote Sens. 2022, 14, 15. https://doi.org/10.3390/ rs14010015

Academic Editors: Rudiger Gens and Jiafu Mao

Received: 5 November 2021

Accepted: 17 December 2021

Published: 21 December 2021

Publisher's Note: MDPI stays neutral with regard to jurisdictional claims in published maps and institutional affiliations.

Copyright: (c) 2021 by the authors. Licensee MDPI, Basel, Switzerland. This article is an open access article distributed under the terms and conditions of the Creative Commons Attribution (CC BY) license (https:// creativecommons.org/licenses/by/ $4.0 /)$.

\begin{abstract}
Monitoring vegetation net primary productivity (NPP) is very important for evaluating ecosystem health. However, the nonlinear characteristics of the vegetation NPP remain unclear in the six provinces along the Maritime Silk Road in China. In this study, using NDVI and meteorological data from 1982 to 2015, NPP was estimated with the Carnegie-Ames-Stanford Approach (CASA) model based on vegetation type dynamics, and its nonlinear characteristics were explored through the ensemble empirical mode decomposition (EEMD) method. The results showed that: (1) The total NPP in the changed vegetation types caused by ecological engineering and urbanization increased but decreased in those caused by agricultural reclamation and vegetation destruction, (2) the vegetation NPP was dominated by interannual variations, mainly in the middle of the study area, while by long-term trends, mainly in the southwest and northeast, (3) for most of the vegetation types, NPP was dominated by the monotonically increasing trend. Although vegetation NPP in the urban land mainly showed a decreasing trend (monotonic decrease and decrease from increase), there were large areas in which NPP increased from decreasing. Although vegetation NPP in the farmland mainly showed increasing trends, there were large areas that faced the risk of NPP decreasing; (4) dynamical changes of vegetation type by agricultural reclamation and vegetation destruction made the NPP trend monotonically decrease in large areas, leading to ecosystem degradation, while those caused by urbanization and ecological engineering mainly made the NPP increase from decreasing, leading to later recovery from early degradation. Our results highlighted the importance of vegetation type dynamics for accurately estimating vegetation NPP, as well as for assessing their impacts, and the importance of nonlinear analysis for deepening our understanding of vegetation NPP changes.
\end{abstract}

Keywords: net primary productivity (NPP); multiple time scales; nonlinear trend; vegetation type dynamics; EEMD method

\section{Introduction}

The net primary productivity (NPP) of vegetation, the amount of organic matter accumulated by green plants in unit time and unit area, directly reflects the productivity of a plant community. The NPP can determine the carbon sources and sinks in an ecosystem; 
thus, it plays a very important role in the global change and carbon balances [1-6]. Evaluating the change in the vegetation, NPP cannot only help us understand the changes in vegetation NPP, but also further evaluate the ecosystem health [7].

With the development of remote sensing technology, parameter models for estimating NPP with remote sensing have become more and more widely used due to their easy and simple operation. The theoretical basis of the parametric model is the mechanism of plant photosynthesis, that is, the model of the light energy utilization rate [8]. The CarnegieAmes-Stanford Approach (CASA), a parametric model proposed by Potter, et al. [9], has been improved by Piao, et al. [10] and $\mathrm{Zhu}$, et al. [11] in recent years. It requires the normalized difference vegetation index (NDVI), total solar radiation, temperature, and precipitation data with few easily obtained parameters, and thus, is considered to be one of the most appropriate models for estimating the vegetation NPP at large scales [9]. In recent years, many scholars have used the CASA model to estimate the vegetation NPP, and further explored its temporal trends, persistence, and mutations from local to global scales [12-19]. In these studies, the CASA model assumed that the vegetation types remained unchanged. In reality, under the impacts of human activities, the vegetation types changed a great deal. In addition, previous studies on the impacts of vegetation type changes on vegetation NPP only considered the changes between the start and the end years. They can only analyze the statistical changes of vegetation type, but not the dynamical changes of vegetation type throughout the whole period. Thus, ignoring vegetation type dynamics cannot reflect the process of vegetation type, which makes it difficult to truly reflect the impact of vegetation type changes on vegetation NPP. Therefore, the vegetation type dynamics must be considered to improve the accuracy of the NPP calculation and to assess their impacts on vegetation NPP.

Although numerous studies have monitored the changes in the vegetation NPP [20,21], most of them focused on the linear and monotonic trend with linear regression or the Manner-Kendall trend detecting method [22,23], and its nonlinear characteristics remain unclear. Vegetation changes are nonlinear and non-stationary [23,24]. Therefore, the changes in the vegetation NPP are also nonlinear, characterized by variations of multiple time scales and nonlinear trend. Thus, it is urgently needed to reveal the nonlinear characteristics to accurately assess the vegetation NPP changes. Liu, et al. [22] and Jia, et al. [25] successfully explored the multi-time scale characteristics and nonlinear trend of the vegetation NPP in northwest China using the EEMD method, a widely used multiple-time scale analysis method [26]. However, they did not consider the dynamics of vegetation types when estimating the vegetation NPP and assessing their impacts. Affected by human activities, such as ecological engineering, urbanization, and agricultural reclamation, vegetation types inevitably changed from time to time on a large scale [27-30] and had great impacts on the vegetation NPP. Thus, the NPP cannot be accurately estimated and the impacts of vegetation type changes on the vegetation NPP cannot be well studied when ignoring the dynamical changes of vegetation types.

The six coastal provinces along the southeast China are the most developed economy area in China with frequent human activities [31]. With the advancement of urbanization, the rapid development of trade, and large-scale agricultural reclamation, human activities had affected the dynamics of vegetation types and greatly changed vegetation NPP, further threatening ecosystem health [32-34]. In addition, coastal zones with strong land-ocean interactions are very sensitive to climate changes and human activities [35]. Therefore, under the dual pressure of human activities and climate change, the ecology of this area is relatively fragile. However, there are currently few studies that have assessed the NPP changes in coastal ecosystems. With the proposition and implementation of the One Belt One Road policy, this area, as an important passage of the 21st century Maritime Silk Road, has not only ushered in major opportunities for economic development, but also faced huge ecological environmental challenges. Therefore, it is necessary to evaluate the ecosystem health by evaluating vegetation NPP changes. To assess the changes of vegetation NPP accurately, the variations on multiple time scales and the nonlinear trend 
should be explored, both of which remain unclear. Therefore, monitoring the nonlinear characteristics of the vegetation NPP changes by considering vegetation type dynamics is of great significance for evaluating ecosystem health in the areas along the Maritime Silk Road [7,36]. Specifically, the objectives of this study were (1) to calculate the vegetation NPP during 1982-2015 using the CASA model by considering vegetation type dynamics, (2) to reveal multi-time scale variations and the nonlinear trend of the NPP for different vegetation types using the EEMD method, and (3) to assess the influences of vegetation type dynamics on the nonlinear trend of the vegetation NPP.

\section{Materials and Methods}

\subsection{Study Area}

The six provinces along the Maritime Silk Road are located in the coastal areas of China, including Jiangsu, Shanghai, Zhejiang, Fujian, Guangdong and Hainan (Figure 1), including 423 county-level administrative regions with an area of 55,561 square kilometers $\left(108^{\circ} 37^{\prime}-123^{\circ} 10^{\prime} \mathrm{E}, 18^{\circ} 10^{\prime}-35^{\circ} 20^{\prime} \mathrm{N}\right)$. The areas are dominated by a subtropical monsoon climate, and the terrain is mainly mountainous, hilly and plain. The vegetation types are mainly forest and farmland. The temperature of the areas is between $10^{\circ} \mathrm{C} 27^{\circ} \mathrm{C}$ yearround, decreasing from the southeast to the northwest. The annual average precipitation is abundant, greater than $1000 \mathrm{~mm}$ in most of the study area.

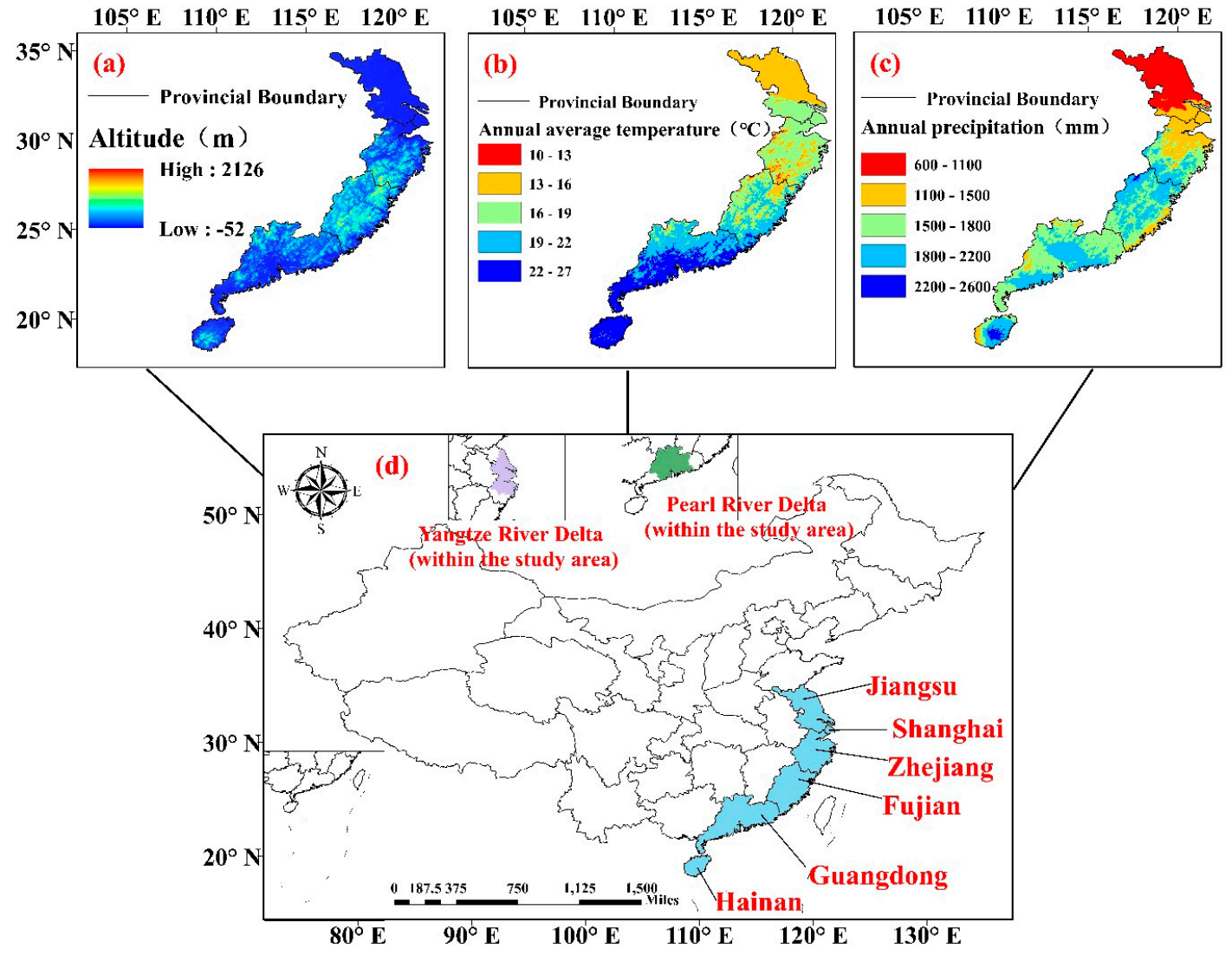

Figure 1. Study area: (a) elevation, (b) average temperature, (c) precipitation, and (d) location of the study area in China.

\subsection{Data Sources}

The NDVI datasets, a fusion product of MODIS and AVHRR data [37,38], were obtained from the Vegetation Index and Phenology (VIP) Laboratory (http: / / vip.arizona.edu / accessed on 16 September 2020), with a $0.05^{\circ}$ spatial resolution during 1982 and 2015 . The data has been corrected for orbital drift, sensor calibration, viewing geometry, volcanic aerosols, atmospheric water vapor, and cloud cover [39-41]. 
The monthly temperature and precipitation data were collected by approximately 75 weather stations, provided by the China Meteorological Science data sharing service network (http: / / data.cma.cn accessed on 16 September 2020). The meteorological data were interpolated to the monthly average temperature and total precipitation data with the same resolution as the NDVI data $\left(0.05^{\circ}\right)$ using the professional meteorological interpolation software ANUSPLIN (https:/ / fennerschool.anu.edu.au/research/products/anusplin; accessed on 16 September 2020) [42].

The vegetation type data for 1992-2015 were obtained from the European Center for Medium Range Weather Forecasts (ECMWF, https: / / cds.climate.copernicus.eu/ accessed on 16 September 2020), with an initial spatial resolution of $300 \mathrm{~m}$. Based on the original 22 categories, the vegetation types were reclassified into 10 categories: evergreen broad-leaved forest, deciduous broad-leaved forest, evergreen coniferous forest, deciduous coniferous forest, mixed forest, farmland, wetland, grassland, shrub and urban land. Usually, long time series analysis requires at least 30 samples [43]. There is no vegetation type data for 1982-1991; however, during that period, the reform and opening up had just begun, there were no large-scale human activities due to economic backwardness in China, and thus the vegetation types changed very little. Therefore, we assumed that the vegetation types remained unchanged from 1982 to 1992, and the calculation of the NPP during that period was based on the vegetation types in 1992. Vegetation type data were resampled to a spatial resolution of $0.05^{\circ}$ using the nearest neighbor interpolation method to match the NDVI data.

The total solar radiation data for 1982-2015 were obtained from the ECMWF (https: / / cds.climate.copernicus.eu/ accessed on 16 September 2020), with a spatial resolution of $0.1^{\circ}$ and a daily time resolution. The daily solar radiation data were summed to monthly data and were resampled to $0.05^{\circ}$ through bilinear interpolation.

\subsection{CASA Model}

The CASA model is based on remote sensing NDVI data, precipitation, temperature, solar radiation, and vegetation types $[9,44]$. The CASA model we used was improved by Piao, et al. [10] and Zhu, et al. [11]. Its structure is shown in Figure 2.

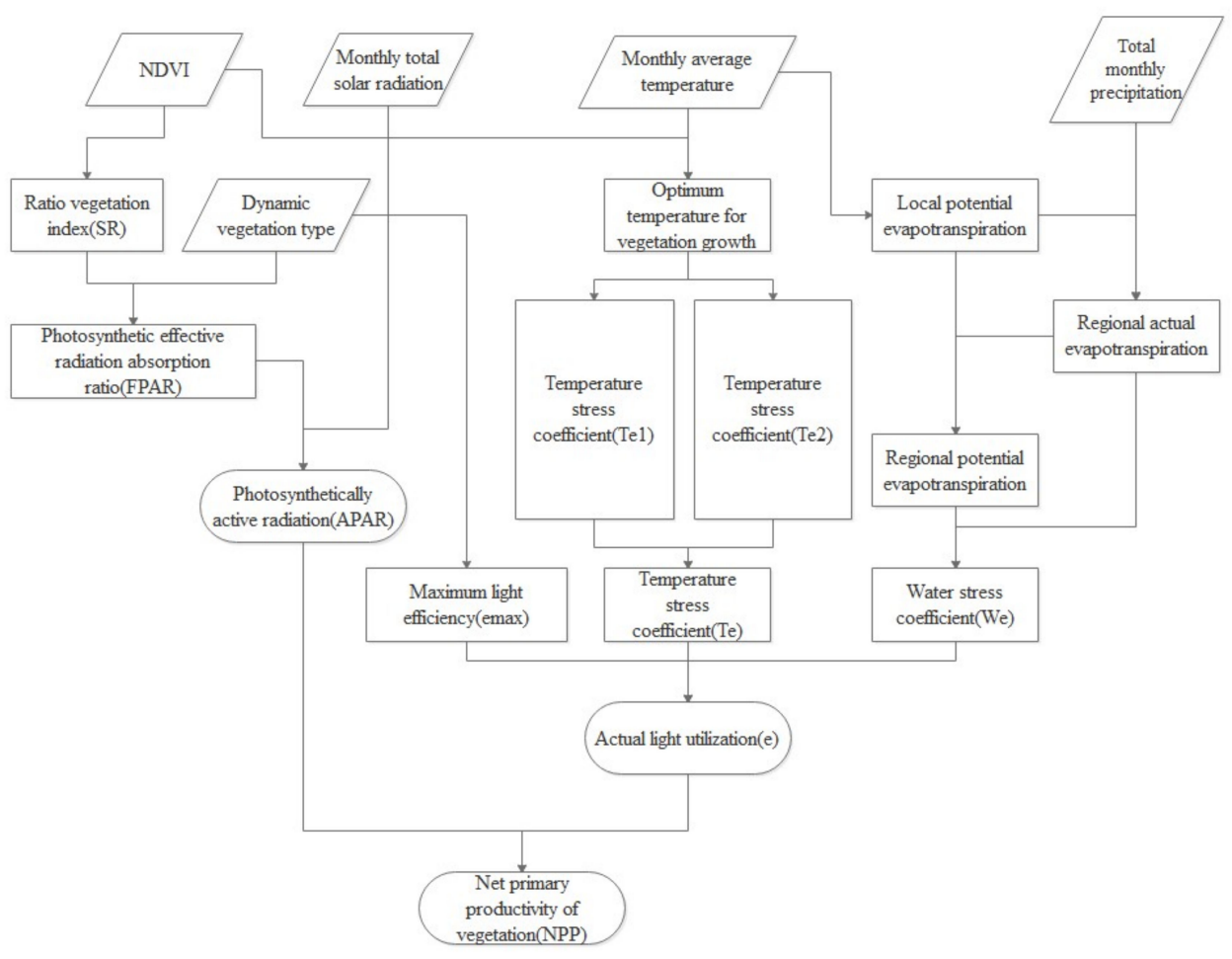

Figure 2. Flowchart of the CASA model. 
The CASA model is determined by the photosynthetic effective radiation (APAR) and the actual light energy utilization $(\varepsilon)$ [45-47], which can be described as follows [10,11]:

$$
\operatorname{NPP}(x, t)=\operatorname{APAR}(x, t) \times \varepsilon(x, t)
$$

$\operatorname{NPP}(x, t), \operatorname{APAR}(x, t)$ and $\varepsilon(x, t)$ are the vegetation NPP, photosynthetically active radiation absorbed, and photosynthetically active radiation absorbed of pixel $x$ in month $t$, respectively [48-51].

The APAR is determined by the total solar radiation (SOL) and the absorption ratio of the photosynthetically active radiation (FPAR):

$$
\operatorname{APAR}(x, t)=\operatorname{SOL}(x, t) \times \operatorname{FPAR}(x, t) \times 0.5
$$

where $\operatorname{SOL}(x, t), \operatorname{FPAR}(x, t)$ are the total solar radiation absorption ratio of the photosynthetically active radiation in pixel $x$ in month $t$, respectively. The value of 0.5 is a rough, widely used estimation of the ratio of the photosynthetically active radiation (PAR) to the total solar radiation $[10,11]$.

The FPAR has a linear relationship with the NDVI [52] and Simple Ratio (SR) Index $[53,54]$. According to this relationship, the FPAR can be determined with the NDVI and SR.

The formula of the FPAR from the NDVI is as follows:

$$
\begin{gathered}
\operatorname{FPAR}_{N D V I}(x, t)=\frac{N D V I(x, t)-N D V I_{\text {min }}}{N D V I_{\max }-N D V I_{\min }} \times\left(F P A R_{\max }-F P A R_{\min }\right) \\
+F P A R_{\text {min }}
\end{gathered}
$$

In Equation (3), NDVI $(x, t)$ is the NDVI in pixel $x$ in month $t . N D V I_{\max }$ and $N D V I_{\min }$ are the maximum and minimum NDVI values of the corresponding vegetation types, respectively. $F P A R_{\max }$ and $F P A R_{\min }$ are set as 0.95 and 0.001 , respectively.

The formula of the ratio vegetation index $S R$ is as follows:

$$
S R(x, t)=\frac{1+\operatorname{NDVI}(x, t)}{1-\operatorname{NDVI}(x, t)}
$$

The FPAR from SR can be calculated as follows:

$$
F P A R_{S R}(x, t)=\frac{S R(x, t)-S R_{\text {min }}}{S R_{\text {max }}-S R_{\text {min }}} \times\left(F P A R_{\text {max }}-F P A R_{\text {min }}\right)+F P A R_{\text {min }}
$$

In Equation (5), $S R_{\max }$ and $S R_{\min }$ are the maximum and minimum $S R$ values of the corresponding vegetation types, respectively.

The final formula for FPAR [55] is as follows:

$$
\operatorname{FPAR}(x, t)=\alpha F P A R_{N D V I}+(1-\alpha) F P A R_{S R}
$$

$\alpha$ is the adjustment coefficient (generally 0.5).

The actual light use efficiency is affected by temperature stress coefficient $\left(T_{\varepsilon 1}, T_{\varepsilon 2}\right)$ and the water stress coefficient $\left(W_{\varepsilon}\right)$ :

$$
\varepsilon(x, t)=\varepsilon_{\max } \times T_{\varepsilon}(x, t) \times W_{\varepsilon}(x, t)
$$

In Equation (7), $\varepsilon_{\max }$ is the maximum light use efficiency of the vegetation, which is an important parameter in the CASA model, greatly affects the final calculation results. Its values changed in different vegetation types, ranging from 0.09 to $2.16 \mathrm{gC} / \mathrm{MJ}$. In this study, we adopted the maximum light use efficiency of the vegetation proposed by Running [56], Running, et al. [57] and Zhu, et al. [58] (Table 1). For a more detailed description of the CASA model, please refer to Piao, et al. [10], Zhu, et al. [11] and Zhu, et al. [58]. 
Table 1. Maximum light utilization rate of the vegetation types in the six provinces along the southeast coast of China.

\begin{tabular}{cc}
\hline Vegetation Types & Maximum Light Utilization (gC/MJ) \\
\hline Deciduous Broad-Leaved Forest & 1.044 \\
Evergreen Broad-Leaved Forest & 1.259 \\
Deciduous Coniferous Forest & 1.103 \\
Evergreen Coniferous Forest & 1.008 \\
Mixed Forest & 1.116 \\
Shrub & 0.888 \\
Grassland & 0.768 \\
Wetland & 0.608 \\
Farmland & 0.608 \\
Urban and Rural Land & 0.542 \\
Other & 0 \\
\hline
\end{tabular}

When estimating NPP with CASA model, previous studies assumed that the vegetation type is unchanged. However, vegetation type can affect FPAR by affecting $N D V I_{\max }$ and $N D V I_{\min }$ in Equation (3), $S R_{\max }$ and $S R_{\min }$ in Equation (5) respectively. Meanwhile, in Equation (7), $\varepsilon_{\max }$ in different pixels varied when the vegetation type changed. Thus, vegetation types can ultimately affect the estimation of NPP by affecting FPAR and $\varepsilon_{\max }$. Thus, we considered that the vegetation type is changed with time when estimating NPP with CASA model.

\subsection{Verification Method of NPP Calculation}

The calculated NPP was usually verified by field investigation and comparison with the results of multiple models or the results of previous studies $[59,60]$. The study area, including six southeast coastal provinces, is too large to verify the NPP using a large number of in-situ measurements. Moreover, there is only one site in the research area in the Fluxnet network (https: / fluxnet.org/ accessed on 16 September 2020), which cannot be used for verification. Therefore, in this study, we chose two widely used datasets for validation [61], that is, the MODIS-17A3HGF series products of the United States from 2000 to $2015[62,63]$ and GLO_PEM based on the light utilization model from the Resource and Environmental Science and Data Center of the Chinese Academy of Sciences (http:/ / www.resdc.cn/data.aspx?DATAID=204; accessed on 9 October) from 2000 to 2010. MODIS-NPP and GLO_PEM-NPP had much higher resolution than our estimated NPP but are only available from 2000 to 2020 and from 2000 to 2010, respectively. Therefore, our study only used these two datasets for NPP verification. These two datasets were resampled to a spatial resolution of $0.05^{\circ}$ using the bilinear interpolation method to match the calculated NPP data.

To evaluate the performance of CASA model; in each year, we compared our estimated CASA-NPP of all pixels (more than 20,000 pixels) in the study area with the MODIS-NPP and GLO_PEM-NPP using a linear regression method, respectively. When constructing the linear regression, our estimated CASA-NPP was set as a dependent variable, while the MODIS-NPP/GLO_PEM-NPP was set as independent variable. Then, the coefficient of determination $\left(R^{2}\right)$ and the root mean square error (RMSE), two widely used statistics for validation [64-68], were calculated for each year, and used to validate the modeled NPP. These two statistics can be described as follows [69]:

$$
\begin{gathered}
R^{2}=\left(\frac{\sum_{i=1}^{n}\left(X_{i}-X\right)\left(Y_{i}-Y\right)}{\sqrt{\sum_{i=1}^{n}\left(X_{i}-X\right)^{2}} \sqrt{\sum_{i=1}^{n}\left(Y_{i}-Y\right)^{2}}}\right)^{2} \\
R M S E=\sqrt{\frac{\sum_{i=1}^{n}\left(X_{i}-Y_{i}\right)^{2}}{n}}
\end{gathered}
$$

where $Y_{i}$ and $X_{i}$ represents our estimated NPP and the NPP for comparison in pixel $i$, respectively. $Y$ and $X$ are their mean values of all pixels. 
This $R^{2}$ is a measure of how well the regression fits the actual data. It varies between $0-1$, the more the value approaches 1 , the better the result is $[70,71]$. A model with high $R^{2}$ and low RMSE were considered as a good model [72].

\subsection{Ensemble Empirical Mode Decomposition (EEMD) Method}

The EEMD method is based on empirical mode decomposition (EMD) [73], which can be used to divide a non-stationary time series into a finite set of components with a decreasing frequency and a residual trend [26]. The original data was composed with a certain proportion of white noise into new signal. The characteristics of different scales and secular trend in the new signal are decomposed step by step. Then, the set average is carried out to make the added white noise cancel and to generate a series of signals with different characteristics intrinsic mode function (IMFs) and a trend component (residue) [74]. The decomposed IMF component is based on the local time scale characteristics of the sequence itself. Each IMF component represents the change in the original time series on a different time scale. The residue reflects the long-term trend of the original sequence. This method avoids the interference damage of the original signal information and can solve the problem of mode aliasing caused by the discontinuous signal interval.

The decomposition steps of the EEMD [75] are as follows:

1. Add a Gaussian white noise series $w_{1}(t)$ to the original data $x(t)$. The amplitude of the Gaussian white noise series was set to 0.2 times standard deviation of the original data.

$$
x_{1}(t)=x(t)+w_{1}(t)
$$

2. Form the upper and lower envelope curves of the time series data $x_{1}(t)$ by connecting local maxima and minima with cubic splines, respectively; then the time series data $x_{1}(t)$ minus the mean value $m_{1}(t)$ of the upper and lower envelope curves.

$$
f_{1}(t)=x_{1}(t)-m_{1}(t)
$$

3. Determine whether $f_{1}(t)$ satisfies the given criterion (close enough to zero at anywhere). If yes, stop sifting. Otherwise, take $f_{1}(t)$ as a new time series data and repeat step 2. In this way, obtain the first IMF: $i m f_{1}(t)$.

$$
\begin{gathered}
f_{2}(t)=f_{1}(t)-m_{2}(t) \\
i m f_{1}(t)=f_{k}(t)=f_{k-1}(t)-m_{k}(t)
\end{gathered}
$$

4. Obtain the remainder $R_{1}(t)$ by subtracting $i m f_{1}(t)$ from $x_{1}(t)$. If $R_{1}(t)$ still contains oscillatory component; repeat 2 and 3 but with $R_{1}(t)$ being the new time series data.

$$
\begin{gathered}
R_{1}(t)=x_{1}(t)-i m f_{1}(t) \\
R_{n}(t)=R_{n-1}(t)-i m f_{n}(t)
\end{gathered}
$$

Thus, $x_{1}(t)$ is decomposed into $n$ IMFs with decreasing frequencies and a residual trend that is monotonic or has at most one extremum.

$$
x_{1}(t)=\sum_{j=1}^{n} i m f_{j}(t)+R_{n}(t)
$$

5. Repeat steps $1-4$ for $l$ times ( $l$ was set to 100 in this study) with different Gaussian white noise series added each time. Obtain the ensemble means of the corresponding IMFs and trends of the decompositions as the final results.

A MATLAB EEMD package is downloadable at http: / / rcada.ncu.edu.tw / research1.htm accessed on 16 September 2020. 
The EEMD trend of NPP at a certain time $t$ is represented as the increase of the $R_{n}$ value since the start time, 1982 , that is:

$$
\operatorname{Trend}(t)=R(t)-R_{n}(1982)
$$

For the trends that are time-varying, their rates of change are also temporally local quantities and can be calculated as:

$$
\text { Rate }_{\text {trend }}(t)=\operatorname{Trend}(t)-\operatorname{Trend}(t-1)
$$

For EEMD trends, we also conducted a significance test approach to test the EEMD trends [76-78]. The detailed process is as follows:

1. Generate 5000 white noise sequences with the same time length as the NPP sequences and conduct EEMD to extract their long-term trend.

2. Divide the EEMD trend of the spatial location by the standard deviation of the corresponding NPP data.

3. It was found that the propagation value of 1.64 times the standard deviation of the white noise sequence trend is the $90 \%$ confidence interval.

4. Judge whether the trend value is outside the confidence interval. If it is outside the confidence interval, it is considered significant, otherwise it is considered insignificant.

Based on the significance of the EEMD trend, the nonlinear trend of the EEMD can be divided into five categories (Table 2).

Table 2. The nonlinear trend of the EEMD.

\begin{tabular}{cc}
\hline Type & Description \\
\hline No significant change & the trend is not significant in any year \\
Monotonic increase/decrease & the trend exhibits a monotonic increase/decrease with \\
statistical significance in at least one year & \\
$\begin{array}{c}\text { Initial increase then decrease/Initial } \\
\text { decrease then increase }\end{array}$ & $\begin{array}{c}\text { the trend initially increases and then decreases / decreases and } \\
\text { then increases, including a local maximum/minimum, with } \\
\text { statistical significance in at least one year }\end{array}$ \\
\hline
\end{tabular}

\subsection{Classification of Changed and Unchanged Vegetation Types by Considering Vegetation Type Dynamics}

In this study area, the area of changed vegetation type is indeed not large, but the impact of vegetation type changes on NPP cannot be ignored. We used 2015 NPP minus 1982 NPP and calculated each pixel by taking the absolute value to judge the change of $\mathrm{NPP}$; we found that the average NPP change was $162.53 \mathrm{gC} / \mathrm{m}^{2} /$ year, while the average NPP change of unchanged vegetation type was $156.57 \mathrm{gC} / \mathrm{m}^{2} /$ year, and the average NPP change of changed vegetation type was $193.63 \mathrm{gC} / \mathrm{m}^{2} /$ year. In total, the NPP change was $3080 \mathrm{kgC} /$ year, while the total NPP change of the changed vegetation type was $590 \mathrm{kgC} /$ year, accounting for close to $20 \%$, which should not be ignored. Thus, changes in vegetation types had a great impact on vegetation NPP, especially for areas where vegetation NPP reduced. Exploring the impacts of changes of vegetation types on vegetation NPP changes will provide some scientific reference for ecological protections and recovery.

In this study, vegetation types were divided into changed and unchanged vegetation types by considering dynamics of vegetation type. To represent the process types of vegetation changes, we have compared the spatial distribution of vegetation types in each year from 1992 to 2015 pixel-by-pixel. If the vegetation type in one pixel kept unchanged during the whole period, it was assumed as an unchanged vegetation type in that pixel. If the vegetation type changed in any year, it was assumed as a changed vegetation type. For changed vegetation types, it was possible that there were several times of interconversion among different vegetation types during the whole period. If vegetation type A changed to vegetation type B, and B kept unchanged for $n$ years, then we assumed the vegetation type changes from A to B lasted for $n$ years. If there are several times of such changes of vegetation type from $A$ to $B$, we will sum the lasting time of each change, and finally get the 
total lasting time of the changed vegetation types from A to B. We will calculate the total lasting time of each kind of change of vegetation type from one to another and determine the changes of vegetation types with the longest lasting time as the classification of the changed vegetation type.

There were 11 vegetation types in the study area (Figure 3); thus, there were a possible 110 categories of changed vegetation types $(11 \times 10)$. In fact, when we performed spatial overlaying analysis for the changes of vegetation types during 1992-2015 in ArcMap10.3, there were only 95 categories of changed vegetation types. It would be too complicated to analyze all of them. In addition, the study area was located in the most developed economy area of China with intense human activities such as urbanization, agricultural reclamation, ecological engineering, and so on. Thus, we assumed that the changes of vegetation type were mainly caused by human activities. To reduce the complexity of changes of vegetation types, we reclassified the changes into four categories as the following:

1. Changed vegetation type caused by ecological engineering: conversion of nonvegetated land to vegetated land, farmland and urban land to forestland or grassland, and grassland to forestland.

2. Changed vegetation type caused by urbanization: conversion of forestland, grassland, and farmland to urban and rural construction land.

3. Changed vegetation type caused by agricultural reclamation: conversion of woodland, grassland and unused land into farmland.

4. Changed vegetation type caused by vegetation destruction: conversion of vegetated land such as forestland, grassland, and farmland into non-vegetated land.

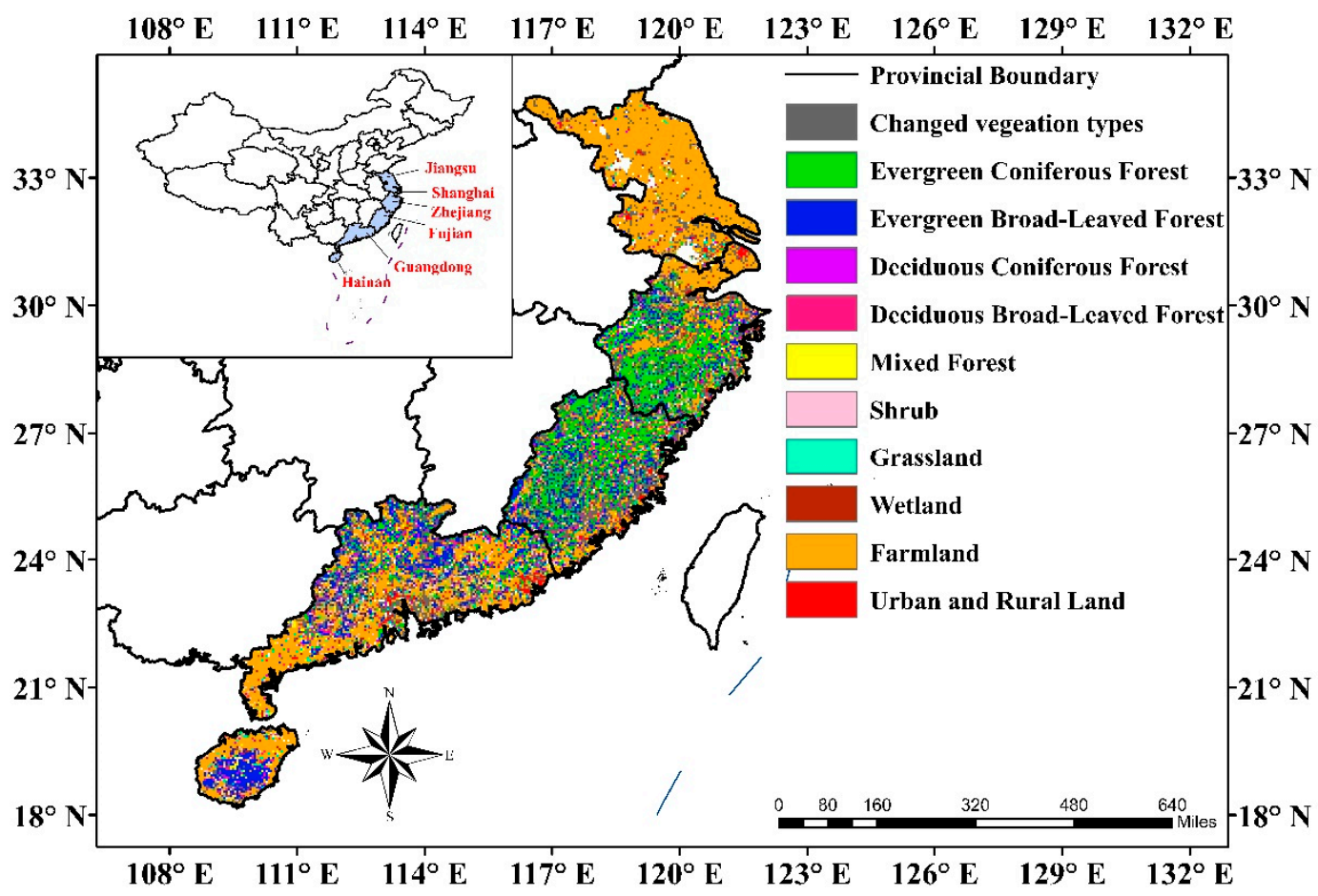

Figure 3. Unchanged (evergreen broad-leaved forest, deciduous broad-leaved forest, evergreen coniferous forest, deciduous coniferous forest, mixed forest, farmland, wetland, grassland, shrub, urban and rural land) and changed vegetation types in the study area during 1992-2015. The white areas in the study area representing the non-vegetation type.

Different from previous studies that only considered the start and end year during the study period, we considered the vegetation types in each year, that is, vegetation type dynamics during the whole study period. So, in this study, the unchanged and changed vegetation types can be used to better represent the process of vegetation type changes 
and more accurately assess the impacts of vegetation type dynamics on vegetation NPP. To assess the influence of vegetation type dynamics on the nonlinear trend of the vegetation NPP, we analyzed the spatial distribution and area percentages of different types of the nonlinear trends in 11 categories of unchanged vegetation types and four categories of changed vegetation types.

\section{Results}

\subsection{Verification of NPP Calculation}

As can be seen from Figure $4 \mathrm{a}$, the NPP calculated in this study are between the MODISNPP and GLO_PEM-NPP. For RMSE, the average RMSE compared with the MODIS-NPP and GLO_PEM-NPP are $123.75 \mathrm{gC} / \mathrm{m}^{2}$ and $210.79 \mathrm{gC} / \mathrm{m}^{2}$ (Figure 4c), respectively. $R^{2}$ between our modelled NPP and MODIS-NPP and GLO-PEM NPP in each year are all above and close to 0.8 , respectively (Figure $4 \mathrm{~b}$ ). Thus, the performance of our modelled NPP is good. Moreover, a high $R^{2}$ means that the fluctuation characteristics between two data series are similar; thus, our calculated NPP is suitable and reliable for the subsequent multi-scale analysis in this study.
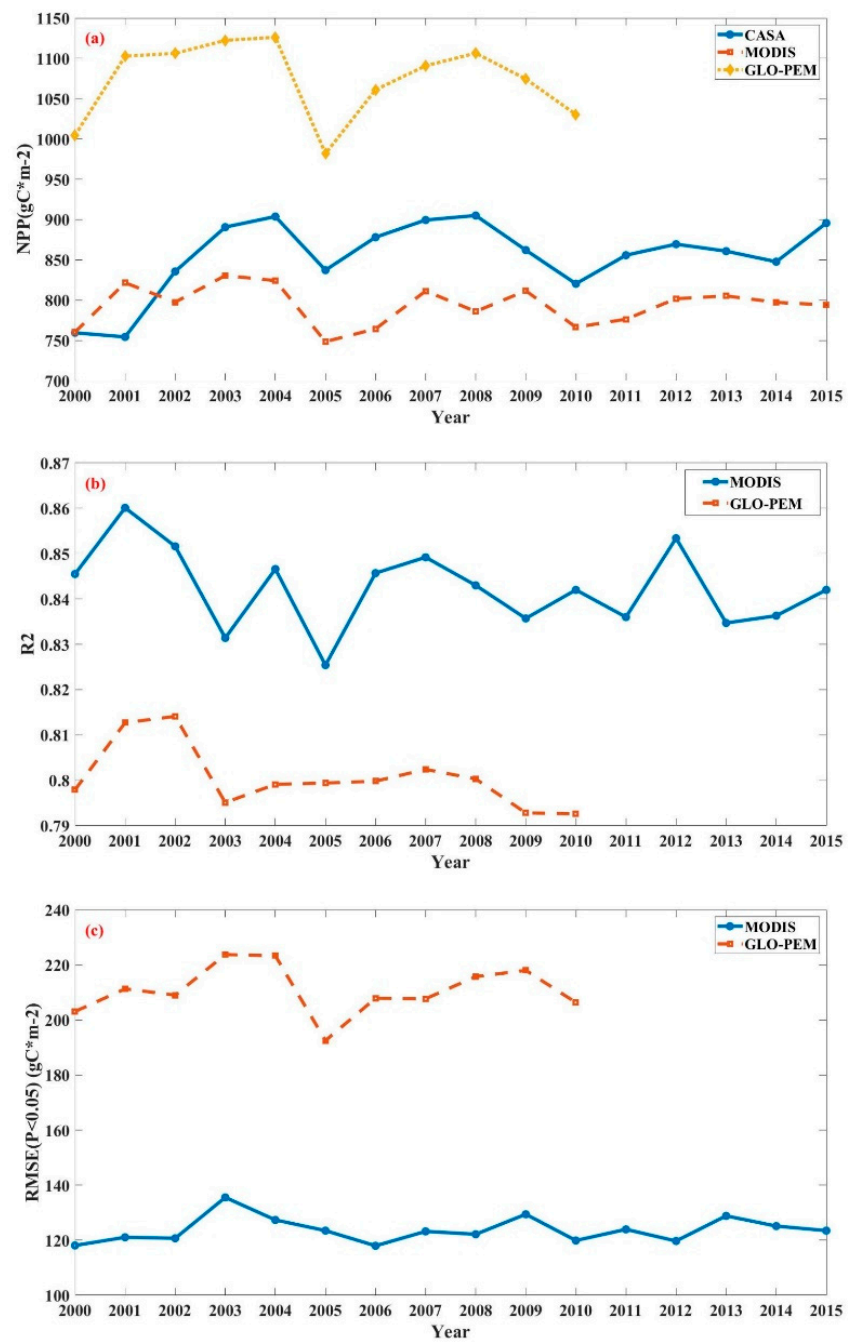

Figure 4. Comparison of the NPP calculation results with the MODIS-17A3HGF data during 2000-2015, and with the GLO_PEM data during 2000-2010,respectively: (a) temporal changes in the estimated NPP obtained using the CASA model and the NPP from MODIS and GLO-PEM, (b) the $R^{2}$ of the CASA-NPP fitted by the MODIS-NPP and GLO_PEM-NPP, (c) the RMSE $t$ of the CASA-NPP fitted by the MODIS-NPP and GLO_PEM-NPP. 


\subsection{Spatial Distribution of the Average Annual NPP}

The average annual, maximum and minimum NPP during 1982-2015 in this area was $837.07 \mathrm{gC} / \mathrm{m}^{2} /$ year, $2792.19 \mathrm{gC} / \mathrm{m}^{2} /$ year, and $35.39 \mathrm{gC} / \mathrm{m}^{2} /$ year, respectively. The average NPP decreased from the southwest to the northeast (Figure 5).

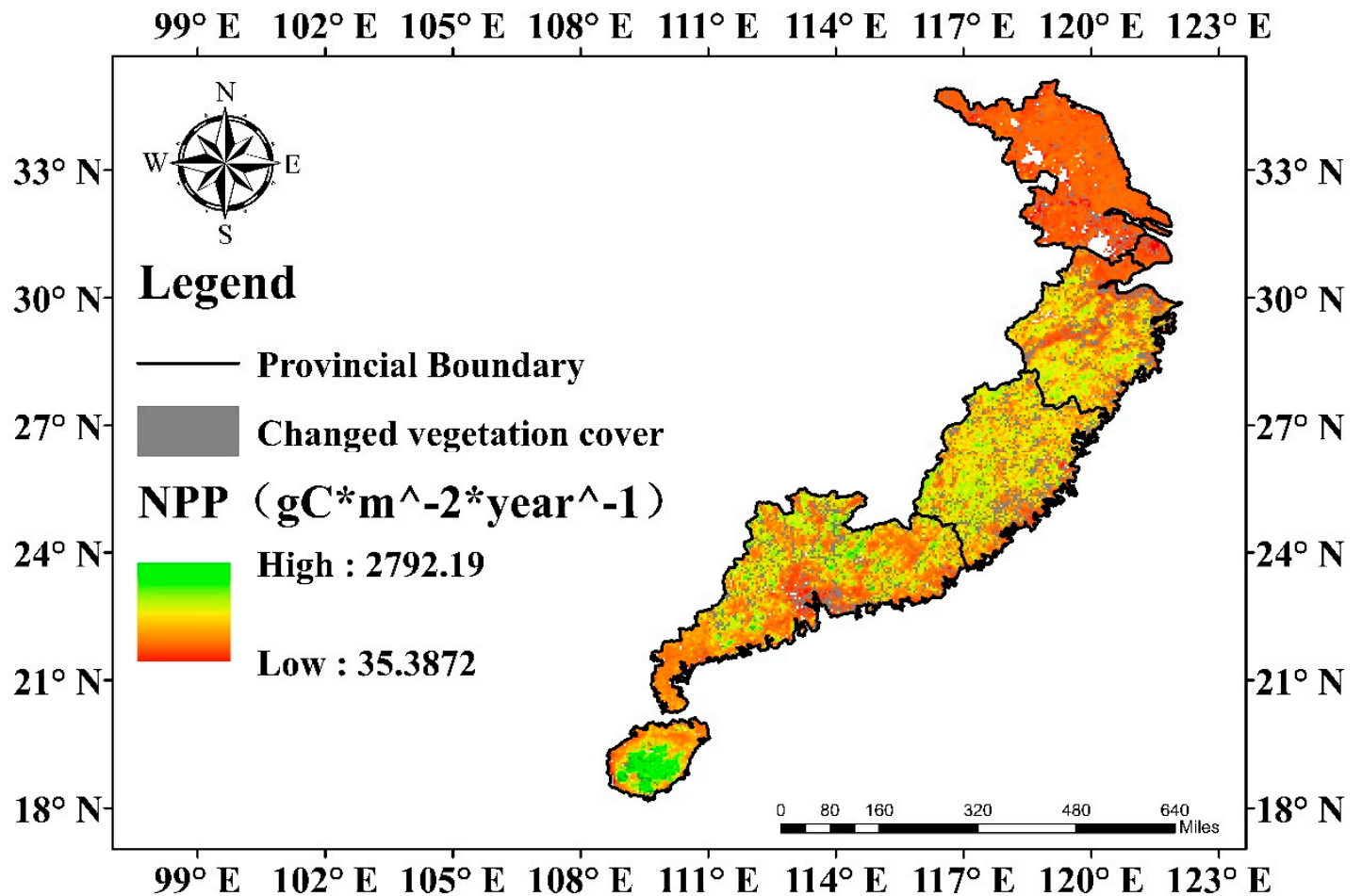

Figure 5. Spatial distribution of the average annual NPP in the six provinces along the southeast coast of China in the unchanged vegetation types from 1982 to 2015.

To study the NPP of the different vegetation types and their multi-time scale characteristics, we extracted the unchanged vegetation types during 1982-2015 (Table 3).The average annual value of the NPP per unit area in different vegetation types ranked from the largest to the smallest as follows: evergreen broad-leaved forest $>$ mixed forest $>$ deciduous coniferous forest $>$ deciduous broad-leaved forest $>$ evergreen coniferous forest $>$ shrub $>$ grassland $>$ wetland $>$ farmland $>$ urban and rural land.

Table 3. Annual mean NPP of the unchanged vegetation types in the six provinces along the southeast coast of China.

\begin{tabular}{|c|c|c|c|c|c|c|c|c|c|c|}
\hline Vegetation Types & ECF & EBF & DCF & DBF & MF & SH & GL & WL & FL & UGL \\
\hline$\left(1+n_{0}\right.$ & 407811 & 7014172 & 1364904 & 3045 & 22 & 11,0 & 21 & 32 & .06 & 8649.18 \\
\hline Area & 18. & 15 & 2. & 2.8 & 2.6 & 3.2 & 2.29 & 3.29 & 47. & 1.89 \\
\hline & 106 & 1396.92 & 1183.89 & 1113.12 & 1190.52 & 915.57 & 791.75 & 610.88 & 537.77 & 390.19 \\
\hline Tota & 8959.18 & 9798 & 16 & 1452 & 146 & 1362.80 & 830.41 & 918.05 & $11,555.45$ & 337.48 \\
\hline Percentage of Total NPP (\%) & 23.40 & 25.59 & 4.22 & 3.79 & 3.81 & 3.56 & 2.17 & 2.40 & 30.18 & 0.88 \\
\hline
\end{tabular}

NOTE: ECF-Evergreen Coniferous Forest, EBF-Evergreen Broad-Leaved Forest, DCF-Deciduous Coniferous Forest, DBF-Deciduous Broad-Leaved Forest, MF—Mixed Forest, SH—Shrub, GL—Grassland, WL-Wetland FL-Farmland, UGL-Urban and Rural Land.

\subsection{Changes in the Vegetation NPP during 1982-2015}

3.3.1. NPP Changes of the Unchanged Vegetation Types

The NPP changes per unit area of the evergreen broad-leaved forests were larger than those of the other vegetation types, while that of urban and rural land was the smallest and decreased (Table 4). However, the farmland contributed the most to the total NPP changes $(67.16 \%)$, followed by the evergreen coniferous forests and evergreen broad-leaved forests. 
Table 4. Contribution of the different unchanged vegetation types to the total NPP changes in the six provinces along the southeast coast of China.

\begin{tabular}{|c|c|c|c|c|c|c|c|c|c|c|}
\hline Vegetation Types & ECF & EBF & DCF & DBF & MF & SH & GL & $\mathbf{W L}$ & FL & UGL \\
\hline NPP Changes Per Unit A & 152.10 & 194.6 & 167.4 & 164.9 & 161.94 & 44. & 106.06 & 79. & 96.10 & -10.88 \\
\hline Total NP & $39,195.20$ & 34,9 & 1154 & 102 & 891 & 11 & 431 & 668 & 74.19 & -29.82 \\
\hline Contribution to Total NPP Change (\%) & 16.18 & 14.44 & 0.48 & 0.42 & 0.37 & 0.48 & 0.18 & 0.28 & 67.16 & 0.01 \\
\hline
\end{tabular}

NOTE: ECF-Evergreen Coniferous Forest, EBF-Evergreen Broad-Leaved Forest, DCF-Deciduous Coniferous Forest, DBF-Deciduous Broad-Leaved Forest, MF—Mixed Forest, SH-Shrub, GL—Grassland, WL-Wetland, FL-Farmland, UGL-Urban And Rural Land.

\subsubsection{NPP Changes of the Changed Vegetation Types}

We use the vegetation NPP in 2015 and the vegetation NPP in 1982 to subtract and extract the NPP changes of all pixels under the changed vegetation type (Table 5). The changes of NPP in the changed vegetation types were mainly caused by reclamation and urbanization, accounted for $53.43 \%$ and $38.76 \%$, respectively. In addition, the NPP changes caused by the reclamation and urbanization were much greater than those caused by ecological engineering and vegetation destruction. In particular, the proportion of the change in the vegetation NPP caused by agricultural reclamation was as high as $58.92 \%$, which was the main reason for the decrease in the vegetation NPP. However, urbanization led to an increase in the vegetation NPP. Although the proportion of the ecological greening project area was small, the proportion of the NPP increase caused by the ecological greening project was high $(15.87 \%)$.

Table 5. 2015-1982 NPP variation of all pixels and the absolute value of its proportion under the changed vegetation types.

\begin{tabular}{|c|c|c|c|c|c|}
\hline Vegetation Change Types & Ecological Engineering & Urbanization & Agricultural Reclamation & Vegetation Destruction & Summary \\
\hline Area $\left(\mathrm{km}^{2}\right)$ & 3546.92 & $22,393.72$ & $30,870.27$ & 961.88 & $57,772.79$ \\
\hline Area Percentage (\%) & 6.14 & 38.76 & 53.43 & 1.66 & 100 \\
\hline NPP Variation $\left(\mathrm{gC} / \mathrm{m}^{2} /\right.$ year $)$ & $49,889.18$ & $26,809.73$ & $-121,900.9$ & $-13,350.09$ & $-58,552.08$ \\
\hline $\begin{array}{l}\text { Sum of Absolute Value of } \\
\text { NPP Variation }\left(\mathrm{gC} / \mathrm{m}^{2} / \text { year }\right)\end{array}$ & $50,326.49$ & $65,590.67$ & $186,869.09$ & $14,359.83$ & $317,146.09$ \\
\hline $\begin{array}{c}\text { Proportion of Sum of } \\
\text { Absolute Value of NPP } \\
\text { Change (\%) }\end{array}$ & 15.87 & 20.68 & 58.92 & 4.53 & 100 \\
\hline
\end{tabular}

\subsection{Multi-Time Scale Variations of the Vegetation NPP}

The NPP was decomposed into four IMF components and one increasing trend at the regional scale (Figure 6). The average periods of the four IMF components were $\sim 3,6,15$, and 32 years (Table 6). The variance contribution of the IMF1 was the largest, accounting for $41.01 \%$, followed by the long-term trend $(26.62 \%)$. In addition, the contribution of the variation on the 6-year time scale was greater than $17 \%$, indicating that the interannual variations including 3- and 6-year time scales dominated the vegetation NPP changes. Thus, vegetation NPP was vulnerable to external disturbance at short timescales. We also noticed that the variance contribution rate on the 15 -year time scale was greater than $10 \%$, which also means that interdecadal changes cannot be ignored. 


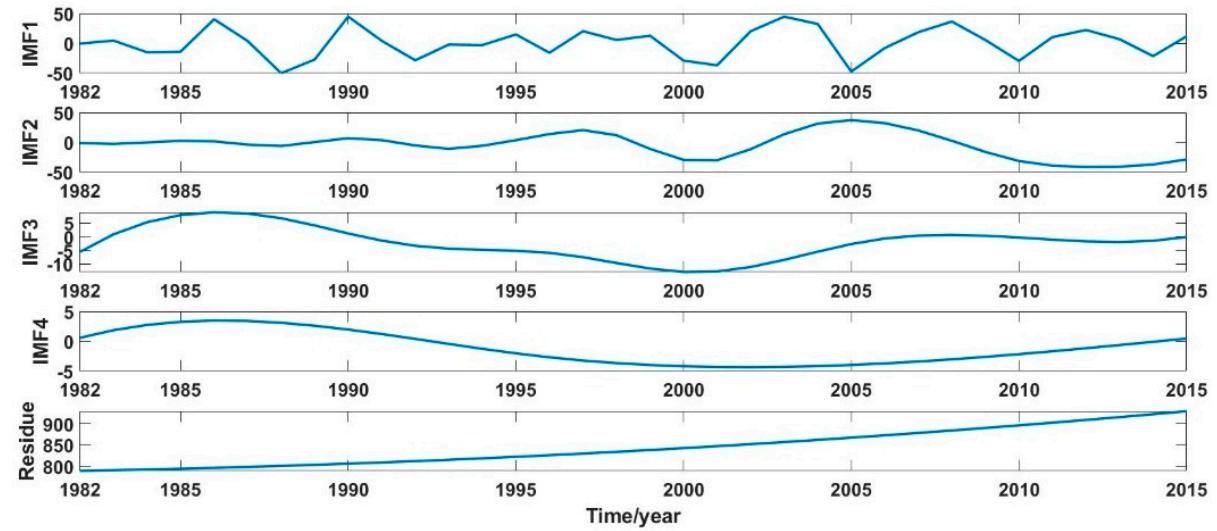

Figure 6. EEMD analysis of the average NPP changes during 1982-2015. IMF1-IMF 4 and Residue representing variations on different time scales and long-term trend, respectively.

Table 6. Variance contribution rate (VC, \%) and average period (year) of the average NPP change of all pixels on different time scales.

\begin{tabular}{ccccccc}
\hline Variable Types & Statistical Indicators & IMF1 & IMF2 & IMF3 & IMF4 & Residue \\
\hline \multirow{2}{*}{ Period } & Mean & 3 & 6 & 15 & 32 & - \\
& Std & 0.32 & 1.17 & 3.99 & 5.99 & - \\
\multirow{2}{*}{ Variance Contribution } & Mean & 41.01 & 17.68 & 11.96 & 2.72 & 26.62 \\
& Std & 15.84 & 10.32 & 9.2 & 4.59 & 20.73 \\
\hline
\end{tabular}

On the 3-year time scale, in most of the study area, especially in the middle of the study area dominated by woodland, the variance contribution rate was greater than $36 \%$ (Figure 7a). However, in the northeastern and southwestern parts dominated by farmland, mixed with a small amount of urban and rural land, the variance contributions were less than $36 \%$.

On the 6-year time scale, $58.69 \%$ of the regions had variance contribution rates of less than $18 \%$. However, the spatial distributions of the variance contribution rates on the 6-year and 3-year time scales were similar, that is, low in the southwest and northeast but high in the middle.

On the 15-year time scale, variance contribution rates were mostly smaller than $10 \%$. Only $38.75 \%$ of the areas had variance contribution rates greater than $12 \%$, mainly distributed in northeast Hainan and southwest Guangdong, in northwest Jiangsu.

For the long-term trend, the variance contribution rates in some areas of central and southern Fujian, southwest Guangdong and eastern and northwestern Hainan were also greater than $29 \%$, which indicated that long-term trends were also important for vegetation NPP changes.

In summary, vegetation NPP is controlled by interannual variations in the middle of the study area, dominated by the woodland with the largest increment per unit area, while controlled by long-term trend in the northeastern and southwestern parts, dominated by the farmland with the highest contribution to the total NPP increment. 

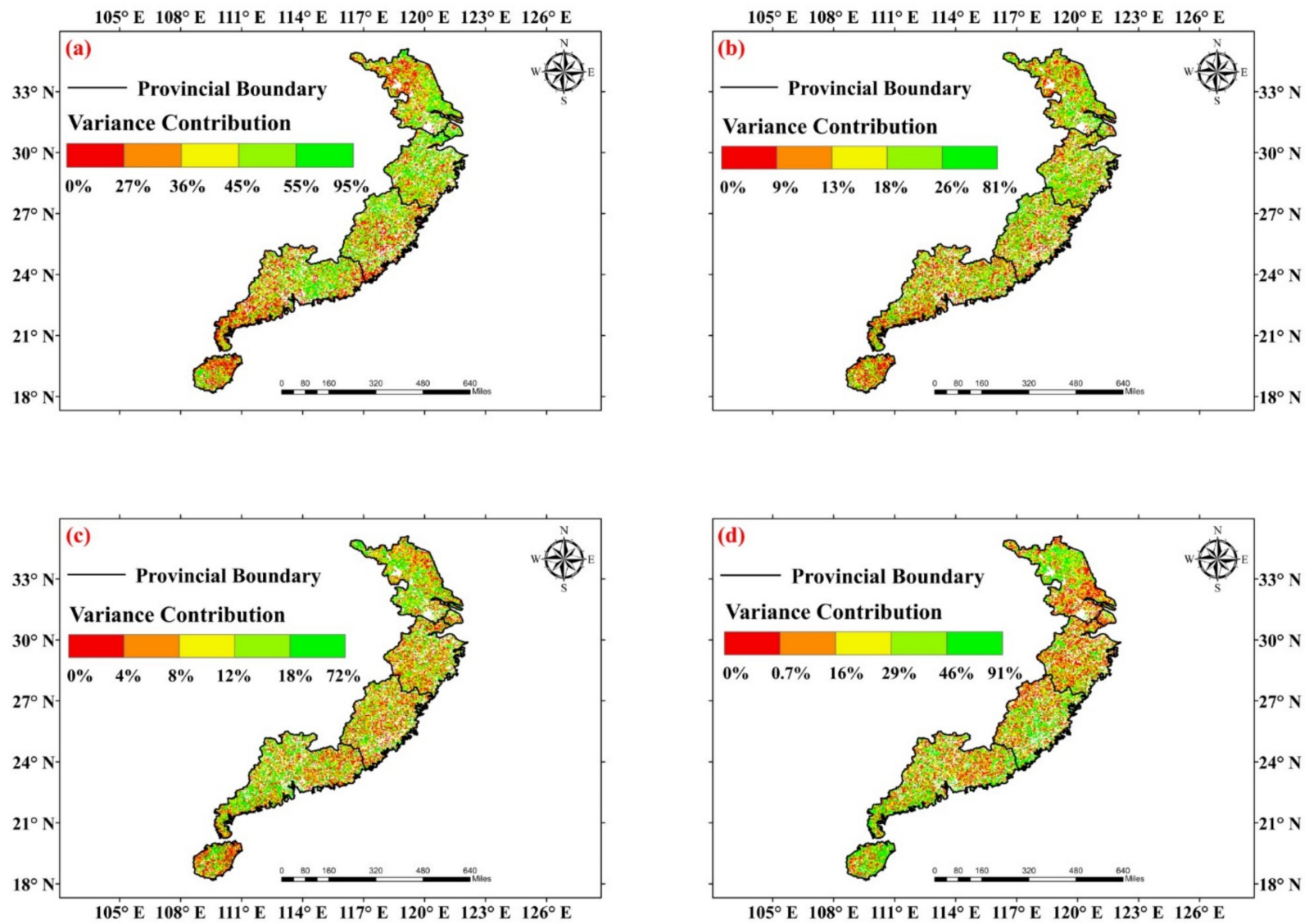

Figure 7. Spatial distribution of the variance contribution rates of different time scales to NPP changes, classified using 20\% quantiles: (a) 3-year time scale, (b) 6-year time scale, (c) 15-year time scale, and (d) long-term trend.

\subsection{Spatial Distribution of the Nonlinear Trend of the Vegetation NPP}

\subsubsection{Nonlinear Trend of the Vegetation NPP in Unchanged Vegetation Types}

The vegetation NPP in large areas (37.03\%) exhibited an insignificant trend, mainly in the northern-central part of the study area dominated by evergreen coniferous forest, evergreen broad-leaved forest, and farmland (Figure 8a).

For the significant nonlinear trend, the monotonic increasing trend accounted for greater than 30\%, mainly in Hainan, the Lei Zhou Peninsula in southwest Guangdong, northeast Fujian, and northern Jiangsu, mainly dominated by farmland, evergreen broadleaved forest, and deciduous broad-leaved forest. In addition, the proportions of area that the NPP trend changed from decreasing to increasing trends were as high as $17 \%$, mainly in northern Hainan, western Guangdong and near the Pearl River Delta, which is dominated by farmland and urban-rural land mixed with a small amount of evergreen broad-leaved forest. This showed that almost half of this area in the ecosystem was monotonically improved or improved from degradation.

Moreover, although the proportion of monotonic decrease was very small (3.93\%), the proportion that the NPP trend changed from increase to decrease reached $10.63 \%$, mainly in parts of central and southern Jiangsu and a small part of Fujian, which is dominated by mainly farmland and evergreen coniferous forest. It demonstrated that the ecosystems in these areas were facing the risk of degradation from recovery. 

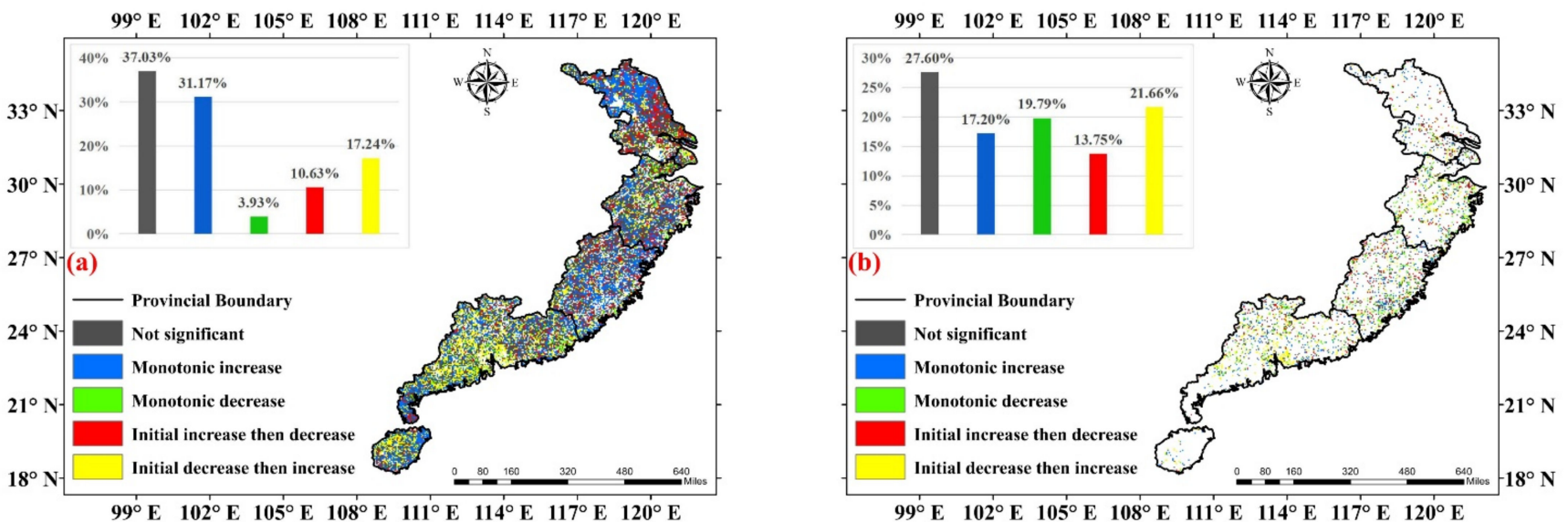

Figure 8. Spatial distribution of the non-linear trend of the vegetation NPP changes: (a) unchanged vegetation types, and $(\mathbf{b})$ changed vegetation types. The white areas in $(\mathbf{a}, \mathbf{b})$ representing the changed and unchangedvegetation types, respectively.

The proportion of insignificant change in all of the vegetation types was higher than that for each significant change type, especially for most of the forest and wetland vegetation (Table 7). Moreover, for the significant changes, except for the urban and rural land, most of the vegetation types were dominated by monotonic increase trends, around 30\%, indicating that most of the vegetation NPP was improved, except for the urban and rural land. Meanwhile, except for the urban and rural land and the evergreen coniferous forest, the proportion of areas with the trend that initially decreased and then increased for the other vegetation types was close to $20 \%$, indicating the great potential for ecosystem recovery. Although the proportion of areas that underwent monotonic decrease was very low for most of the vegetation types, except for the urban and rural land, the proportion of areas that initially increased and then decreased was close to $10 \%$, indicating some risk of NPP decreasing, especially for the evergreen coniferous forest and farmland.

Table 7. Area percentage (\%) of the nonlinear trend classification under different vegetation types.

\begin{tabular}{|c|c|c|c|c|c|}
\hline Vegetation Types & Not Significant & Monotonic Increase & Monotonic Decrease & $\begin{array}{c}\text { Initial Increase then } \\
\text { Decrease }\end{array}$ & $\begin{array}{c}\text { Initial Decrease } \\
\text { then Increase }\end{array}$ \\
\hline \multirow{2}{*}{$\begin{array}{c}\text { Evergreen Coniferous Forest } \\
\text { Evergreen Broad-Leaved } \\
\text { Forests }\end{array}$} & 40.29 & 32.09 & 2.26 & 10.39 & 14.97 \\
\hline & 38.67 & 29.95 & 3.2 & 8.23 & 19.95 \\
\hline \multirow{2}{*}{$\begin{array}{c}\text { Deciduous Coniferous Forest } \\
\text { Deciduous Broad-Leaved } \\
\text { Forest }\end{array}$} & 37.47 & 29.47 & 3.58 & 8.63 & 20.84 \\
\hline & 34.36 & 33.48 & 2.86 & 9.25 & 20.04 \\
\hline Mixed Forest & 38.88 & 29.51 & 3.75 & 6.09 & 21.78 \\
\hline Shrub & 35.33 & 31.85 & 2.32 & 9.07 & 21.43 \\
\hline Grassland & 35.07 & 29.86 & 4.11 & 7.95 & 23.01 \\
\hline Wetland & 39.01 & 27.72 & 3.63 & 9.37 & 20.27 \\
\hline Farmland & 35.36 & 32.28 & 4.44 & 12.33 & 15.59 \\
\hline Urban and Rural Land & 35.88 & 12.62 & 18.94 & 9.97 & 22.59 \\
\hline
\end{tabular}

\subsubsection{Nonlinear Trend of the Vegetation NPP in Changed Vegetation Types}

For the changed vegetation types (Figure 8b), the proportion of areas of the insignificant change in the trend were much lower than for the unchanged vegetation types, indicating that the vegetation type changes changed the vegetation NPP greatly. In addition, the areas of monotonic trends were very close to the areas of trend reversal. Unlike the unchanged vegetation types, the vegetation NPP was dominated by an initial decrease and then an increase $(21.66 \%)$, and by a monotonic decrease $(19.79 \%)$. The trends of areas that initially decreased and then increased and monotonically increased were mainly distributed in the central part of Zhejiang, the coastal areas of Fujian, central Guangdong, the Pearl River Delta, and its adjacent coastal areas, which accounted for $38.86 \%$. The trends of initial increase and then decrease and then monotonic decrease mainly occurred in northwest 
and southeast Fujian, southern Jiangsu, some of the coastal areas of Zhejiang, and some of central and northern Guangdong, which accounted for 33.54\%. Although the proportion of NPP monotonic increase and increased from decreasing trends were very large (close to $40 \%)$, the proportion of NPP decrease was also very large $(>30 \%)$, that is, the changes in the vegetation type may have led to both the improvement and degradation.

Except for urbanization (40.13\%) and agricultural reclamation (21.91\%), the proportion of non-significant NPP change was very low in the changed vegetation types (Table 8). The trends of NPP in changed vegetation types caused by ecological engineering and urbanization were mainly dominated by trend reversal from decreasing to increasing and monotonic increase. This showed that ecological engineering was conducive to ecosystem restoration. Meanwhile, after urbanization had caused a certain amount of damage to the vegetation NPP, it also caused some degree of ecosystem restoration. It should be noted that agricultural reclamation caused a large part (35.44\%) of the vegetation NPP to exhibit a monotonic decrease. In addition, although $17.04 \%$ of the agricultural reclamation gave NPP the potential to transition from decreasing to increase, $16.85 \%$ was at a risk of transitioning from increasing to decrease. Vegetation destruction led NPP to a monotonic decrease and trend reversal from increasing to decreasing (37.5\% and $25 \%$, respectively).

Table 8. Area percentage (\%) of nonlinear trend classification of changed vegetation types.

\begin{tabular}{|c|c|c|c|c|}
\hline Nonlinear Trend Classification & Ecological Engineering & Urbanization & Agricultural Reclamation & Vegetation Destruction \\
\hline Not significant & 9.32 & 40.13 & 21.91 & 0 \\
\hline Monotonic increase & 41.53 & 16.38 & 8.76 & 0 \\
\hline Monotonic decrease & 0.85 & 9.4 & 35.44 & 37.5 \\
\hline Initial increase then decrease & 3.39 & 11.41 & 16.85 & 25 \\
\hline Initial decrease then increase & 44.92 & 22.68 & 17.04 & 37.5 \\
\hline
\end{tabular}

\section{Discussion}

\subsection{Vegetation NPP Changes in Changed and Unchanged Vegetation Types during 1982-2015}

For the different vegetation types, the average annual value of the NPP per unit area was similar to the research results of Piao, et al. [10]. Chen, et al. [79] found that forestland is the main source of the NPP. Similarly, our results show that the proportions of the total NPP occupied by evergreen coniferous forest and evergreen broad-leaved forest were the two highest in the study area; however, the proportion occupied by farmland was also very high. The possible reason for this is that the improvement in agricultural production conditions and climate warming increased the crop yield [80,81], and thus increased the NPP of the farmland vegetation.

From 1982 to 2015, the vegetation NPP increased in most areas, which is consistent with the research results of Wen, et al. [82]. This may be due to the overall warming of the coastal areas. The increase in the daytime temperature promoted photosynthesis and increased the NPP [4]. Moreover, the increase in the concentration of $\mathrm{CO}_{2}$ due to anthropogenic activity, and the resultant fertilization effect, also promoted an increase in the vegetation NPP $[83,84]$. For the different vegetation types, the evergreen broad-leaved forest had the largest increase in the NPP per unit area, which is consistent with the results of Mao, et al. [85]. This may be because the warming climate and closing hillsides for afforestation promoted the substantial increase in the NPP per unit area of the forestland. Piao, et al. [86] found that woodland plays an irreplaceable role in China's vegetation greening, and we found that NPP increase per unit area in woodland is much higher than other vegetation types, indicating that woodland has a promoting effect on the vegetation greening and the increase in the NPP. However, the farmland contributed the most to the total increase in the NPP, which is consistent with the results of Pan, et al. [87]'s finding that the NPP of farmland has increased nearly 3-4 times. It is because farmland had the largest area and a high increase in the NPP per unit area due to the increases in nitrogen use and irrigation, and the improvement of agricultural techniques [88], and the large area of farmland, also contributed to the largest increase in the NPP of farmland [89]. In addition, 
we found that the total urban and rural land NPP decreased, which likely reflects the fact that the natural ecological environment of the coastal cities is under great pressure due to population migration and economic development, and thus, the NPP decreased [90].

Liu, et al. [91] pointed out that changes in land use will cause a decrease in the NPP. However, we found that vegetation type changes caused by different human activities have different effects on the NPP. Vegetation type changes caused by ecological engineering and urbanization increased the NPP, whereas those caused by agricultural reclamation and vegetation destruction decreased the NPP. Ecological engineering promoted the expansion of forestland and thus increased the NPP [92]. Agricultural reclamation changed the original high productivity vegetation to farmland and thus reduced the vegetation NPP $[93,94]$; Cao, et al. [95] pointed out that urbanization and desertification cause a decrease in the NPP. Liu, et al. [96] also pointed out that urbanization hinders vegetation greening. We found that vegetation destruction did reduce the vegetation NPP, and the vegetation NPP of the unchanged urban land did decrease a little, which was consistent with Yang, et al. [97]'s finding that, in urban land, NDVI mostly showed a significant downward trend. However, new urban and rural land increased the NPP of the vegetation. The reason for this may be that since the 20th century, the coupling coordination degree between the urbanization and ecological environment in the coastal cities has continuously improved; thus, the ecological environment has improved [90]. Moreover, the eastern coastal area of the study area, which is economically developed, can invest a large amount of funds in new urban land to improve the urban environment, thus increasing the total NPP [21]. In addition, due to the lack of proper management and human activities, vegetation destruction in some areas caused vegetation browning, further decreasing the NPP.

\subsection{Variations in the Vegetation NPP on Multiple Time Scales}

On the regional scale, the NPP changes in the six coastal provinces along Southeast China were mainly dominated by a 3-year cycle and an increasing trend, with variance contribution rates of $41.01 \%$ and $26.62 \%$, respectively, which was consistent with the results of Wang, et al. [98], that is, annual NPP exhibited a fluctuating growth trend from 1982 to 2012. Our results were similar to those of Jia, et al. [25] and Xu, et al. [99]. However, our study revealed that the NPP variations on the 6-year time scale also contributed a lot to the changes in the vegetation NPP (17.68\%). In addition, the spatial distributions of interannual variations on the 3-year and 6-year time scales were similar, while the distributions of the long-term variations on the 15-year time scale and the long-term trend are similar. This indicates that the interannual variations had a greater impact on the vegetation NPP in the central region of the study area, mainly dominated by woodland. This means that woodland is easily affected by short-term disturbances, while the long-term scale changes had a greater impact in the southwestern and northeastern parts, where the vegetation types were dominated by farmland. It means that the farmland is not susceptible to short-term disturbances under human management, and the ecosystem is stable [100]. For the entire study area, the interannual variations on the 3-year and 6-year time scales dominated the changes. Thus, there is still a great risk posed by the external driving factors, and measures should be taken to protect the vegetation ecosystem from short term disturbances [101].

\subsection{Effects of Vegetation Types on Nonlinear Trends in the Vegetation NPP}

Although the vegetation in China exhibited a greening trend [86], and previous studies have found that significant changes have taken place in the farmland, urban and rural land, and woodland in the southeastern coastal area [102-104], our study found that 37.03\% of the vegetation NPP did not change significantly, especially in most of the woodlands and wetlands. Only 31.17\% exhibited a monotonic increase trend, mainly in the northeastern, southwestern, and central coastal areas, which were mainly dominated by farmland and woodland. This indicated that the improvement of agricultural production conditions and the advancement of agricultural technology $[88,105,106]$, and ecological protection projects, have increased the forest NPP [107]. However, although the vegetation NPP of the 
farmland was mainly dominated by monotonic increase and initial decrease then increase, the proportions of the trends that underwent initial increase then decrease and monotonic decrease trends ( $>16 \%$ ) were much larger than the other vegetation types, which indicates that there was a greater risk of NPP decreasing in some farmlands. The possible reason is that, with increasing economic development, a large area of farmlands was abandoned due to the migration of farmers to cities, and thus, the vegetation NPP decreased [108,109]. The vegetation NPP of most of the vegetation types, except for the urban and rural land, was dominated by the monotonic increase trend and the trend of initial decrease and then increase. It may be due to the implementation of the ecological protection project in the coastal areas since 2010, which included ecosystem restoration and afforestation [110]. For the urban and rural land, the proportion of the monotonic decrease trends (18.94\%) and the trend that initially increased and then decreased $(9.97 \%)$ were very large. In the meantime, the proportions of monotonic increase trends $(12.62 \%)$ and trends that initially decreased and then increased (22.59\%) were also very high. It demonstrated that that urbanization could bring about not only the negative [111], but also positive, effects on vegetation NPP [112]. It is worth noting that the trend of the vegetation NPP in $10 \%$ of the study area initially increased and then decreased, indicating that there is a risk of NPP decreasing in these areas. Especially for the evergreen coniferous forests, the proportion of areas of the initial increase then decrease trend were very close to the proportion of areas of the initial decrease then increase trend, indicating coexistence of ecosystem recovery and degradation. Therefore, non-linear analysis of the trends can explore the hidden recovery potential and the possible degradation risks [113].

\subsection{Effects of Vegetation Type Dynamics on the Nonlinear Trend of the Vegetation NPP}

Although some studies have revealed the impacts of land use change on changes in the vegetation NPP $[91,95,114]$, they just considered the land use changes between the start and end years, and few studies investigated the influence of the dynamics of vegetation type during the whole periods on the nonlinear trend of the vegetation NPP. Except for changed vegetation types caused by urbanization, the dynamics of vegetation types led to significant changes in the vegetation NPP. Vegetation dynamics caused by agricultural reclamation and vegetation destruction mainly led to a monotonic decrease in the vegetation NPP; thus vegetation NPP decreased. Agricultural reclamation replaced the original vegetation types with higher NPP, such as woodland and shrubs [94], thus leading to a decrease in the vegetation NPP. Previous studies have found that urbanization leads to a decrease in the vegetation NPP $[82,115,116]$. However, the results of this study show that dynamics of vegetation type caused by urbanization mainly caused the trend of the vegetation NPP to initially decrease and then increase or to monotonically increase, which also confirms that urbanization had dual effects on vegetation NPP [97]. That is, urbanization led to not only vegetation NPP increase, but also to an increase from decreasing. Because the areas along the Maritime Silk Road are highly developed, lots of funds have been invested in urban green spaces in order to improve urban greening, which has caused the trend of the vegetation NPP to reverse from decreasing to increase and has led to direct vegetation NPP increase [117]. In addition, the urban heat island effect increases the temperature cities, which promotes increasing vegetation NPP [21]. Since 1978, China has implemented large-scale ecological engineering, which led to many areas of vegetation greening [118]. We found that ecological engineering led to not only vegetation NPP increase but also more vegetation NPP increase from decreasing trends, which is similar to the existing research results [119-121]. This is explained by the fact that the ecological protection projects [120] have increased the vegetation coverage and the richness of vegetation species [119]; in addition, the increase in vegetation has slowed down the local soil erosion, which is beneficial to the NPP of vegetation [121]. 


\subsection{Limitation and Future Direction}

In this study, we verified our CASA-based NPP by comparing with two widely used data sets, including MODIS-NPP and GLO_PEM-NPP because of unavailability of enough field data in a large region; thus, there may be some uncertainty in our results. MODIS-NPP and GLO_PEM-NPP had much higher resolution than our estimated NPP but are only available from 2000 to 2020 and from 2000 to 2010, respectively. Usually, at least 30 years of data is needed for long time series analysis such as the EEMD method to ensure the reliability of the results [43]. In addition, since the time range of our research is 1982-2015, the highest spatial resolution of the data we could find was $0.05^{\circ}$; thus, the differences between the regions shown on our pictures are relatively rough and need to be combined with related tables for analysis. To obtain long time series of NPP with high resolution to reduce uncertainty, we can attempt to fuse the existing high resolution NPP products with our estimate of NPP in the future.

By considering the vegetation dynamics, we estimated vegetation NPP with CASA model during 1982-2015. However, there is no data of vegetation types meeting our research requirements during 1982 to 1991. Thus, we assumed that there was no change in vegetation types during 1982-1991, which may cause some uncertainties in estimating the NPP because there may exist small changes in vegetation types [122]. Therefore, future research should be devoted to extracting a much longer time series of vegetation types.

In this study, we focused on the nonlinear characteristic of vegetation NPP when considering vegetation type dynamics, and only considered the effects of dynamics of vegetation types caused by human activities on the trends of vegetation NPP, ignoring the influence of climate change. Climate change, especially for extreme climates [86,123-125], had a huge impact on vegetation NPP [126-129]. Thus, we will explore the impacts of these climate parameters on the long-term trend of NPP in future direction. In addition, the rising $\mathrm{CO}_{2}$ concentration over the past decades can enhance plant photosynthesis by accelerating the rate of carboxylation $[80,130,131]$. Moreover, the enhanced nitrogen deposition over China in recent decades significantly increased plant foliar $\mathrm{N}$ concentrations in plants [132], which may stimulate photosynthesis and thus enhance the uptake of atmospheric $\mathrm{CO}_{2}$. Therefore, in future works, we will try to explore the driving forces of vegetation NPP trends by considering both human and nature factors.

\section{Conclusions}

In this study, the vegetation NPP in the six coastal provinces along Southeast China from 1982 to 2015 were calculated using the CASA model by considering vegetation type dynamics; In addition, the nonlinear characteristics of the changes in the NPP were explored using the EEMD method.

The total vegetation NPP increased in most areas. The NPP per unit area of the evergreen broad-leaved forest increased the most; however, the total increment of the NPP of farmland was the largest due to the large area. Vegetation NPP was dominated by interannual variations on 3-year and 6-year time scales, and thus were likely to be sensitive to external disturbances. The woodland, which had the largest increment per unit area, distributed in the middle of the study area, was controlled by interannual variations. The farmland, which made the highest contribution to the total increment of the NPP, distributed in the northeastern and southwestern parts of the study area, was dominated by the long-term trend. Ecological engineering and urbanization increased the total NPP, while vegetation destruction and agricultural reclamation decreased the total NPP. Most vegetation types, except for urban and rural land, were dominated by monotonically increasing trends; however, NPP also faced potential reduction risks, because the proportion of areas with an initially increasing and then decreasing trend were close to $10 \%$. Vegetation type dynamics resulted from agricultural reclamation and vegetation destruction caused the NPP trend to monotonically decrease in a large area, leading to vegetation NPP reduction. However, Vegetation type dynamics from urbanization and 
ecological engineering mainly caused the vegetation NPP trend to reverse from decreasing to increase, resulting in vegetation NPP enhancement.

Revealing the nonlinear characteristics of the NPP of different vegetation types is helpful in deepening our understanding of vegetation changes and further accurately assessing the ecosystem health. Moreover, the effects of the dynamics of vegetation types on the NPP trends showed that human activities bring about not only the challenges of decreasing vegetation NPP but also the opportunity for vegetation NPP increasing in the six coastal provinces along the southeast China.

Author Contributions: Conceptualization, H.L.; Data curation, P.X.; Formal analysis, P.X. and L.C.; Funding acquisition, H.L. and M.Z.; Investigation, P.X.; Methodology, P.X. and H.L.; Project administration, H.L. and M.Z.; Resources, P.X.; Software, P.X.; Supervision, H.L.; Visualization, P.X. and H.G.; Writing-original draft, P.X.; Writing—review \& editing, H.L. All authors have read and agreed to the published version of the manuscript.

Funding: This research was funded by the National Natural Science Foundation of China (No. 41971382, 31870454) and the Priority Academic Program Development of Jiangsu Higher Education Institutions $(164320 \mathrm{H} 116)$.

Institutional Review Board Statement: Not applicable.

Informed Consent Statement: Not applicable.

Data Availability Statement: Not applicable.

Conflicts of Interest: The authors declare no conflict of interest.

\section{References}

1. Dai, E.; Huang, Y.; Wu, Z.; Zhao, D. Spatial-temporal features of carbon source-sink and its relationship with climate factors in Inner Mongolia grassland ecosystem. Acta Geogr. Sin. 2016, 71, 21-34.

2. Huang, D.; Zhang, L.; Yin, X.; Wang, K. Application of image fusion in improving NPP estimation accuracy. Comput. Eng. Appl. 2014, 50, 193-198,232.

3. Wang, X.; Ding, J.; Tan, K.; Li, H. Spatio-Temporal Variation of Net Primary Productivity of Vegetation in Mining Areas of Yuxian and Its Affecting Factors. J. Ecol. Rural Environ. 2016, 32, 187-194.

4. Xu, X.; Jiang, H.; Guan, M.; Wang, L.; Huang, Y.; Jiang, Y.; Wang, A. Vegetation responses to extreme climatic indices in coastal China from 1986 to 2015. Sci. Total Environ. 2020, 744, 140784. [CrossRef]

5. Zeng, J.; Zhang, R.; Tang, J.; Liang, J.; Li, J.; Zeng, Y.; Li, Y.; Zhang, Q.; Shui, W.; Wang, Q. Ecological sustainability assessment of the carbon footprint in Fujian Province, southeast China. Front. Earth Sci. 2020, 15, 1-11. [CrossRef]

6. Zhang, P.; Li, Y.; Jing, W.; Yang, D.; Zhang, Y.; Liu, Y.; Geng, W.; Rong, T.; Shao, J.; Yang, J.; et al. Comprehensive Assessment of the Effect of Urban Built-Up Land Expansion and Climate Change on Net Primary Productivity. Complexity 2020, 2020, 1-12. [CrossRef]

7. Zhou, Y.; Yue, D.; Li, C.; Mu, X.; Guo, J. Identifying the spatial drivers of net primary productivity: A case study in the Bailong River Basin, China. Glob. Ecol. Conserv. 2021, 28, e01685. [CrossRef]

8. Ito, A. A historical meta-analysis of global terrestrial net primary productivity: Are estimates converging? Glob. Chang. Biol. 2011, 17, 3161-3175. [CrossRef]

9. Potter, C.S.; Randerson, J.T.; Field, C.B.; Matson, P.A.; Vitousek, P.M.; Mooney, H.A.; Klooster, S.A. Terrestrial ecosystem production: A process model based on global satellite and surface data. Glob. Biogeochem. Cycles 1993, 7, 811-841. [CrossRef]

10. Piao, S.L.; Fang, J.Y.; Guo, Q.H. Application of CASA model to the estimation of Chinese terrestrial net primary productivity. Acta Phytoecol. Sin. 2001, 25, 603-608.

11. Zhu, W.; Pan, Y.; Zhang, J. Estimation of net primary productivity of Chinese terrestrial vegetation based on remote sensing. Acta Phytoecol. Sin. 2007, 31, 413-424.

12. Boone, R.B.; Conant, R.T.; Sircely, J.; Thornton, P.K.; Herrero, M. Climate change impacts on selected global rangeland ecosystem services. Glob. Chang. Biol. 2018, 24, 1382-1393. [CrossRef]

13. Dengke, L.I.; Jianzhong, F.A.N.; Jinfang, D. Spatial and Temporal Patterns of Net Primary Productivity from 1981 to 2000 in Shaanxi Province. Acta Bot. Boreali-Occident. Sin. 2011, 31, 1873-1877.

14. Duo, A.; Xiong, K.; Zhao, W.; Gong, Z.; Jing, R.; Zhang, L. Temporal Trend of Climate Change and Mutation Analysis of North China Plain During 1960 to 2013. Sci. Geogr. Sin. 2016, 36, 1555-1564.

15. Jiao, W.; Chen, Y.; Li, Z. Remote sensing estimation and the reasons for temporal-spatial differences of vegetation net primary productivity in arid region of Northwest China. Chin. J. Ecol. 2017, 36, 181-189.

16. Li, Z.; Pan, J. Spatiotemporal changes in vegetation net primary productivity in the arid region of Northwest China, 2001 to 2012. Front. Earth Sci. 2018, 12, 108-124. [CrossRef] 
17. Luo, Y.; Wang, X.; Li, F.; Gao, R.; Duan, L.; Liu, T. Responses of grass production to precipitation in a mid-latitude typical steppe watershed. Trans. Asabe 2014, 57, 1595-1610.

18. Pan, J.; Dong, L. Spatio-temporal variation in vegetation net primary productivity and its relationship with climatic factors in the Shule River basin from 2001 to 2010. Hum. Ecol. Risk Assess. 2018, 24, 797-818. [CrossRef]

19. Stefan, H.; Wang, T. Seasonal Change of Terrestrial Net Primary Productivity in China. Progress Geogr. 2010, $24,8-16$.

20. Chen, Y.; Xiao, W. Estimation of Forest NPP and Carbon Sequestration in the Three Gorges Reservoir Area, Using the Biome-BGC Model. Forests 2019, 10, 149. [CrossRef]

21. Guan, X.; Shen, H.; Li, X.; Gan, W.; Zhang, L. A long-term and comprehensive assessment of the urbanization-induced impacts on vegetation net primary productivity. Sci. Total Environ. 2019, 669, 342-352. [CrossRef]

22. Liu, H.; Jia, J.; Lin, Z.; Wang, Z.; Gong, H. Relationship between net primary production and climate change in different vegetation zones based on EEMD detrending-A case study of Northwest China. Ecol. Indic. 2021, 122. [CrossRef]

23. Yu, Z.; Sun, P.; Liu, S. Response of normalized difference vegetation index in main vegetation types to climate change and their variations in different time scales along a North-South Transect of Eastern China. Acta Phytoecol. Sin. 2011, 35, 1117-1126. [CrossRef]

24. Sun, Q.; Liu, T.; Han, Z.; Liu, H.; Dong, H.; Qin, C. Response of climate changes on vegetation cover in north of Tianshan Mountains evaluated using multiple time scales. Trans. Chin. Soc. Agric. Eng. 2014, 30, $248-255$.

25. Jia, J.; Liu, H.; Lin, Z. Multi-time scale changes of vegetation NPP in six provinces of northwest China and their responses to climate change. Acta Ecol. Sin. 2019, 39, 5058-5069.

26. Wu, Z.; Huang, N.E. Ensemble empirical mode decomposition: A noise-assisted data analysis method. Adv. Adapt. Data Anal. 2011, 1, 1-41. [CrossRef]

27. Liu, Z.; Liu, Y.; Li, Y. Anthropogenic contributions dominate trends of vegetation cover change over the farming-pastoral ecotone of northern China. Ecol. Indic. 2018, 95, 370-378. [CrossRef]

28. Luo, Y.; Sun, W.; Yang, K.; Zhao, L. China urbanization process induced vegetation degradation and improvement in recent 20 years. Cities 2021, 114, 103207. [CrossRef]

29. Qiao, Y.; Jiang, Y.; Zhang, C. Contribution of karst ecological restoration engineering to vegetation greening in southwest China during recent decade. Ecol. Indic. 2021, 121, 107081. [CrossRef]

30. Sun, Y.-L.; Shan, M.; Pei, X.-R.; Zhang, X.-K.; Yang, Y.-L. Assessment of the impacts of climate change and human activities on vegetation cover change in the Haihe River basin, China. Phys. Chem. Earth Parts A B C 2020, 115, 102834. [CrossRef]

31. Zhang, X.; Yao, J.; Wang, J.; Sila-Nowicka, K. Changes of forestland in China's coastal areas (1996-2015): Regional variations and driving forces. Land Use Policy 2020, 99, 105018. [CrossRef]

32. Hao, Y.; Ba, N.; Ren, S.; Wu, H. How does international technology spillover affect China's carbon emissions? A new perspective through intellectual property protection. Sustain. Prod. Consum. 2021, 25, 577-590. [CrossRef]

33. Liu, B.; Peng, S.; Liao, Y.; Long, W. The causes and impacts of water resources crises in the Pearl River Delta. J. Clean. Prod. 2018, 177, 413-425. [CrossRef]

34. Yang, C.; Zeng, W.; Yang, X. Coupling coordination evaluation and sustainable development pattern of geo-ecological environment and urbanization in Chongqing municipality, China. Sustain. Cities Soc. 2020, 61, 102271. [CrossRef]

35. Hou, X.; Wu, T.; Hou, W.; Chen, Q.; Wang, Y.; Yu, L. Characteristics of coastline changes in mainland China since the early 1940 s. Sci. China Earth Sci. 2016, 59, 1791-1802. [CrossRef]

36. Li, H.; Hong, Y.; Deng, G.-R.; Wu, R.-H.; Zhang, H.-Y.; Zhao, J.-J.; Guo, X.-Y. Impacts of climate change and human activities on net primary productivity of grasslands in Inner Mongolia, China during 1982-2015. Ying Yong Sheng Tai Xue Bao J. Appl. Ecol. 2021, 32, 415-424. [CrossRef]

37. Jiang, Z.; Huete, A.; Didan, K.; Miura, T. Development of a two-band enhanced vegetation index without a blue band. Remote Sens. Environ. 2008, 112, 3833-3845. [CrossRef]

38. Zhang, X.; Friedl, M.; Schaaf, C.; Strahler, A.; Hodges, J.; Gao, F.; Reed, B.; Huete, A. Monitoring vegetation phenology using MODIS. Remote Sens. Environ. 2003, 84, 471-475. [CrossRef]

39. Rocha, A.V.; Shaver, G.R. Advantages of a two band EVI calculated from solar and photosynthetically active radiation fluxes. Agric. For. Meteorol. 2009, 149, 1560-1563. [CrossRef]

40. Tao, Z.; Wang, H.; Liu, Y.; Xu, Y.; Dai, J. Phenological response of different vegetation types to temperature and precipitation variations in northern China during 1982-2012. Int. J. Remote Sens. 2017, 38, 3236-3252. [CrossRef]

41. Rokni, K.; Musa, T.A. Normalized difference vegetation change index: A technique for detecting vegetation changes using Landsat imagery. Catena 2019, 178, 59-63. [CrossRef]

42. Liu, Z.; Li, L.; Tim, R.M.; Van Niel, T.G.; Yang, Q.; Li, R. Introduction of the Professional Interpolation Software for Meteorology Data: ANUSPLINN. Meteorol. Mon. 2008, 34, 92-100.

43. Xu, Z.; Takeuchi, K.; Ishidaira, H.; Li, J.Y. Long-term trend analysis for precipitation in Asian Pacific FRIEND river basins. Hydrol. Process. 2005, 19, 3517-3532. [CrossRef]

44. Raza, S.M.H.; Mahmood, S.A. Estimation of Net Rice Production through Improved CASA Model by Addition of Soil Suitability Constant ((h)over-bar alpha). Sustainability 2018, 10, 1788. [CrossRef]

45. Qiu, X.; Liu, Y.; Wang, H.; Liu, X.; Chang, H.; Yi, F.; Sun, H. Impacts of precipitation on grassland productivity in Zhenglan Banner, Inner Mongolia. J. Northwest A F Univ. Nat. Sci. Ed. 2017, 45, 31-36. 
46. Qiu, Y.; Fan, D.; Zhao, X.; Sun, W. Spatio-temporal Changes of NPP and Its Responses to Phenology in Northeast China. Geogr. Geo-Inf. Sci. 2017, 33, 21-27.

47. Zhou, X.; Ren, Z.; Li, B.; Zhao, S. Tradeoff and coordination of ecosystem services in Yinchuan basin. J. Shaanxi Norm. Univ. Nat. Sci. Ed. 2017, 45, 104-109.

48. Hu, H.; Su, Z.; Sun, L.; Wei, S. Estimating Net Primary Productivity of Northern Daxing'an Mountain Burned Blank Based on Light Utility Efficiency Model. J. North-East For. Univ. 2013, 41, 71-74.

49. Zhang, C.; Zhang, J.; Wang, P.; Zhang, C. Quantitative Estimation of Ecological Assets in Farming-pasturing Ecotone Based on Remote Sensing and GISA Case Study in Yanchi County, Ningxia. Arid Zone Res. 2013, 30, 356-363.

50. Zhang, F.; Feng, Q.; Li, X.; Wei, Y. Remotely-sensed Estimation of NPP and Its Spatial-temporal Characteristics in the Heihe River Basin. J. Desert Res. 2014, 34, 1657-1664.

51. Li, J.; Wang, H.; Wang, J.; Li, Q.; Zhang, Z.; Liu, L.; Pu, L. Impact of urbanization on terrestrial ecosystem production using Linear Modeling for Jiangsu. Resour. Sci. 2018, 40, 32-43.

52. Ruimy, A.; Saugier, B.; Dedieu, G. Methodology for the estimation of terrestrial net primary production from remotely sensed data. J. Geophys. Res. 1994, 99, 5263-5284. [CrossRef]

53. Field, C.; Randerson, J.; Malmstrom, C. Global Net Primary Production: Combining ecology and remote sensing. Remote Sens. Environ. 1995, 51, 74-88. [CrossRef]

54. Los, S.; Justice, C.; Tucker, C. A global $1 \times 1$ degree NDVI data set for climate studies derived from the GIMMS continental NDVI data. Int. J. Remote Sens. 1994, 15, 3493-3518. [CrossRef]

55. Los, S. Linkages between Vegetation and Climate. An Analysis Based on NOAA AVHRR Data; American Geophysical Union: New York, NY, USA, 1998.

56. Running, S.W. Generalization of a forest ecosystem process model for other biomes, BIOME-BGC, and an application for global-scale models. Scaling Physiol. Process. Leaf Globe 1993, 141-158. [CrossRef]

57. Running, S.; Thornton, P.; Nemani, R.; Glassy, J. Global Terrestrial Gross and Net Primary Productivity from the Earth Observing System. In Methods in Ecosystem Science; Springer: New York, NY, USA, 2000. [CrossRef]

58. Zhu, W.Q.; Pan, Y.; Long, Z.H.; Chen, Y.H.; Li, J.; Hu, H.B. Estimating net primary productivity of terrestrial vegetation based on GIS and RS: A case study in Inner Mongolia, China. J. Remote Sens. 2005, 9, 300.

59. Piao, S.L.; Fang, J.Y.; Guo, Q. Terrestrial net primary production and its spatio-temporal patterns in Qinghai-Xizang Plateau, China during 1982-1999. J. Nat. Resour. 2002, 37, 563-569.

60. Li, C.; Cao, H.; Fan, Y.; Han, H.; Sun, H.; Wang, Y. Remote sensing estimation and analysis of net primary productivity (NPP) based on corrected CASA model: A case study of Hexi Corridor. Acta Ecol. Sin. 2019, 39, 1616-1626.

61. Li, H.; Wu, Y.; Liu, S.; Xiao, J. Regional contributions to interannual variability of net primary production and climatic attributions Agric. For. Meteorol. 2021, 303, 108384. [CrossRef]

62. Zhao, M.; Heinsch, F.A.; Nemani, R.R.; Running, S.W. Improvements of the MODIS terrestrial gross and net primary production global data set. Remote Sens. Environ. 2005, 95, 164-176. [CrossRef]

63. Zhao, M.; Running, S. Drought-Induced Reduction in Global Terrestrial Net Primary Production from 2000 Through 2009. Science 2010, 329, 940-943. [CrossRef]

64. Li, A.; Bian, J.; Lei, G.; Huang, C. Estimating the Maximal Light Use Efficiency for Different Vegetation through the CASA Model Combined with Time-Series Remote Sensing Data and Ground Measurements. Remote Sens. 2012, 4, 3857-3876. [CrossRef]

65. Li, X.; Xiao, J.; Fisher, J.B.; Baldocchi, D.D. ECOSTRESS estimates gross primary production with fine spatial resolution for different times of day from the International Space Station. Remote Sens. Environ. 2021, 258, 112360. [CrossRef]

66. Marshall, M.; Tu, K.; Brown, J. Optimizing a remote sensing production efficiency model for macro-scale GPP and yield estimation in agroecosystems. Remote Sens. Environ. 2018, 217, 258-271. [CrossRef]

67. Olofsson, P.; Eklundh, L. Estimation of absorbed PAR across Scandinavia from satellite measurements. Part II: Modeling and evaluating the fractional absorption. Remote Sens. Environ. 2007, 110, 240-251. [CrossRef]

68. Wang, J.; Li, A.; Bian, J. Simulation of the Grazing Effects on Grassland Aboveground Net Primary Production Using DNDC Model Combined with Time-Series Remote Sensing Data-A Case Study in Zoige Plateau, China. Remote Sens. 2016, 8, 168. [CrossRef]

69. Siabi, Z.; Falahatkar, S.; Alavi, S.J. Spatial distribution of XCO2 using OCO-2 data in growing seasons. J. Environ. Manag. 2019, 244, 110-118. [CrossRef] [PubMed]

70. Raghunatha Reddy, D.V.; Bhramara, P.; Govindarajulu, K. A Comparative Study of Multiple Regression and Artificial Neural Network models for a domestic refrigeration system with a hydrocarbon refrigerant mixtures. Mater. Today Proc. 2020, 22, 1545-1553. [CrossRef]

71. Ridwan, W.M.; Sapitang, M.; Aziz, A.; Kushiar, K.F.; Ahmed, A.N.; El-Shafie, A. Rainfall forecasting model using machine learning methods: Case study Terengganu, Malaysia. Ain Shams Eng. J. 2021, 12, 1651-1663. [CrossRef]

72. Gebreslassie, H.G.; Melesse, A.M.; Bishop, K.; Gebremariam, A.G. Linear spectral unmixing algorithm for modelling suspended sediment concentration of flash floods, upper Tekeze River, Ethiopia. Int. J. Sediment Res. 2020, 35, 79-90. [CrossRef]

73. Wu, Z.H.; Huang, N.E.; Long, S.R.; Peng, C.K. On the trend, detrending, and variability of nonlinear and nonstationary time series. Proc. Natl. Acad. Sci. USA 2007, 104, 14889-14894. [CrossRef] [PubMed] 
74. Du, L.; Song, N.; Wang, L.; Hou, J.; Hu, Y. Impact of GlobalWarming on Vegetation Activity in Ningxia Province from 1982 to 2013. J. Nat. Resour. 2015, 30, 2095-2106.

75. Liu, H.; Zhang, M.; Lin, Z. Relative importance of climate changes at different time scales on net primary productivity-a case study of the Karst area of northwest Guangxi, China. Environ. Monit. Assess. 2017, 189, 539. [CrossRef] [PubMed]

76. Ji, F.; Wu, Z.; Huang, J.; Chassignet, E.P. Evolution of land surface air temperature trend. Nat. Clim. Chang. 2014, 4, 462-466. [CrossRef]

77. Hawinkel, P.; Swinnen, E.; Lhermitte, S.; Verbist, B.; Van Orshoven, J.; Muys, B. A time series processing tool to extract climatedriven interannual vegetation dynamics using Ensemble Empirical Mode Decomposition (EEMD). Remote Sens. Environ. 2015, 169, 375-389. [CrossRef]

78. Jiao, F.; Liu, H.; Xu, X.; Gong, H.; Lin, Z. Trend Evolution of Vegetation Phenology in China during the Period of 1981-2016. Remote Sens. 2020, 12, 572. [CrossRef]

79. Chen, Y.; Chen, L.; Cheng, Y.; Ju, W.; Chen, H.Y.H.; Ruan, H. Afforestation promotes the enhancement of forest LAI and NPP in China. For. Ecol. Manag. 2020, 462, 117990. [CrossRef]

80. Piao, S.; Wang, X.; Park, T.; Chen, C.; Lian, X.; He, Y.; Bjerke, J.W.; Chen, A.; Ciais, P.; Tømmervik, H.; et al. Characteristics, drivers and feedbacks of global greening. Nat. Rev. Earth Environ. 2020, 1, 14-27. [CrossRef]

81. Qiao, F.B. Increasing wage, mechanization, and agriculture production in China. China Econ. Rev. 2017, 46, 249-260. [CrossRef]

82. Wen, Y.; Liu, X.; Bai, Y.; Sun, Y.; Yang, J.; Lin, K.; Pei, F.; Yan, Y. Determining the impacts of climate change and urban expansion on terrestrial net primary production in China. J. Environ. Manag. 2019, 240, 75-83. [CrossRef] [PubMed]

83. Jong, R.; Verbesselt, J.; Schaepman, M.; de Bruin, S. Trend changes in global greening and browning: Contribution of short-term trends to longer-term change. Glob. Chang. Biol. 2012, 18, 642-655. [CrossRef]

84. Rosenzweig, C.; Parry, M. Potential Impact of Climate Change on World Food Supply. Nature 1994, 367, 133-138. [CrossRef]

85. Mao, F.; Du, H.; Li, X.; Ge, H.; Cui, L.; Zhou, G. Spatiotemporal dynamics of bamboo forest net primary productivity with climate variations in Southeast China. Ecol. Indic. 2020, 116, 106505. [CrossRef]

86. Piao, S.; Yin, G.; Tan, J.; Cheng, L.; Huang, M.; Li, Y.; Liu, R.; Mao, J.; Myneni, R.B.; Peng, S.; et al. Detection and attribution of vegetation greening trend in China over the last 30 years. Glob. Chang. Biol. 2015, 21, 1601-1609. [CrossRef]

87. Pan, S.; Tian, H.; Lu, C.; Dangal, S.R.S.; Liu, M. Net primary production of major plant functional types in China: Vegetation classification and ecosystem simulation. Acta Ecol. Sin. 2015, 35, 28-36. [CrossRef]

88. Hong, C.; Jin, X.; Ren, J.; Gu, Z.; Zhou, Y. Satellite data indicates multidimensional variation of agricultural production in land consolidation area. Sci. Total Environ. 2019, 653, 735-747. [CrossRef]

89. Tian, F.; Liu, L.-Z.; Yang, J.-H.; Wu, J.-J. Vegetation greening in more than $94 \%$ of the Yellow River Basin (YRB) region in China during the 21st century caused jointly by warming and anthropogenic activities. Ecol. Indic. 2021, 125, 107479. [CrossRef]

90. Zheng, Z.; Wu, Z.; Chen, Y.; Yang, Z.; Marinello, F. Exploration of eco-environment and urbanization changes in coastal zones: A case study in China over the past 20 years. Ecol. Indic. 2020, 119, 106847. [CrossRef]

91. Liu, F.-H.; Xu, C.-Y.; Yang, X.-X.; Ye, X.-C. Controls of Climate and Land-Use Change on Terrestrial Net Primary Productivity Variation in a Subtropical Humid Basin. Remote Sens. 2020, 12, 3525. [CrossRef]

92. Yang, H.; Mu, S.; Li, J. Effects of ecological restoration projects on land use and land cover change and its influences on territorial NPP in Xinjiang, China. Catena 2014, 115, 85-95. [CrossRef]

93. Yin, L.; Dai, E.; Zheng, D.; Wang, Y.; Ma, L.; Tong, M. What drives the vegetation dynamics in the Hengduan Mountain region, southwest China: Climate change or human activity? Ecol. Indic. 2020, 112, 106013. [CrossRef]

94. Zhang, Y.; Chen, R.; Wang, Y. Tendency of land reclamation in coastal areas of Shanghai from 1998 to 2015. Land Use Policy 2020, 91, 104370. [CrossRef]

95. Cao, F.; Li, J.; Fu, X.; Wu, G. Impacts of land conversion and management measures on net primary productivity in semi-arid grassland. Ecosyst. Health Sustain. 2020, 6, 1749010. [CrossRef]

96. Liu, H.Y.; Jiao, F.S.; Yin, J.Q.; Li, T.Y.; Gong, H.B.; Wang, Z.Y.; Lin, Z.S. Nonlinear relationship of vegetation greening with nature and human factors and its forecast-A case study of Southwest China. Ecol. Indic. 2020, 111, 106009. [CrossRef]

97. Yang, K.; Sun, W.; Luo, Y.; Zhao, L. Impact of urban expansion on vegetation: The case of China (2000-2018). J. Environ. Manag. 2021, 291, 112598. [CrossRef] [PubMed]

98. Wang, M.; Liu, G.; Sun, R.; Xiao, Z. Assessment of NPP dynamics and the responses to climate changes in China from 1982 to 2012. In Proceedings of the 2019 IEEE International Geoscience and Remote Sensing Symposium, Yokohama, Japan, 28 July-2 August 2019; IEEE: Piscataway, NJ, USA, 2019; pp. 6602-6605.

99. Xu, X.; Liu, H.; Lin, Z.; Jiao, F.; Gong, H. Relationship of Abrupt Vegetation Change to Climate Change and Ecological Engineering with Multi-Timescale Analysis in the Karst Region, Southwest China. Remote Sens. 2019, 11, 1564. [CrossRef]

100. Chen, Y.; Yao, M.; Zhao, Q.; Chen, Z.; Jiang, P.; Li, M.; Chen, D. Delineation of a basic farmland protection zone based on spatial connectivity and comprehensive quality evaluation: A case study of Changsha City, China. Land Use Policy 2021, 101, 105145. [CrossRef]

101. Ma, S.; Qiao, Y.-P.; Wang, L.-J.; Zhang, J.-C. Terrain gradient variations in ecosystem services of different vegetation types in mountainous regions: Vegetation resource conservation and sustainable development. For. Ecol. Manag. 2021, $482,118856$. [CrossRef] 
102. Liu, J.; Zhang, Z.; Xu, X.; Kuang, W.; Zhou, W.; Zhang, S.; Li, R.; Yan, C.; Yu, D.; Wu, S.; et al. Spatial patterns and driving forces of land use change in China during the early 21st century. J. Geogr. Sci. 2010, 20, 483-494. [CrossRef]

103. Hua, L.; Zhang, X.; Nie, Q.; Sun, F.; Tang, L. The Impacts of the Expansion of Urban Impervious Surfaces on Urban Heat Islands in a Coastal City in China. Sustainability 2020, 12, 475. [CrossRef]

104. Zhang, S.-X.; Zhang, J.-M.; Zhang, W.-K.; Zhang, D.-N.; Fu, J.-Y.; Zang, C.-F. Spatiotemporal variability characteristics and driving forces of land use in the Pan-Pearl River Basin, China. Ying Yong Sheng Tai Xue Bao J. Appl. Ecol. 2020, 31, 573-580. [CrossRef]

105. Cao, X.; Yuan, L.; Liu, X.; Zhu, L.; Zhu, C.; Kong, Y.; Wu, L.; Tian, C.; Lu, R.; Zhang, J.; et al. Benefits of controlled-release/stable fertilizers plus biochar for rice grain yield and nitrogen utilization under alternating wet and dry irrigation. Eur. J. Agron. 2021, 129, 126338. [CrossRef]

106. Wang, H.; Wu, L.; Wang, X.; Zhang, S.; Cheng, M.; Feng, H.; Fan, J.; Zhang, F.; Xiang, Y. Optimization of water and fertilizer management improves yield, water, nitrogen, phosphorus and potassium uptake and use efficiency of cotton under drip fertigation. Agric. Water Manag. 2021, 245, 106662. [CrossRef]

107. Ying, Z.; Irland, L.; Zhou, X.; Song, Y.; Wen, Y.; Liu, J.; Song, W.; Qiu, Y. Plantation development: Economic analysis of forest management in Fujian Province, China. For. Policy Econ. 2010, 12, 223-230. [CrossRef]

108. Liu, T.; Liu, H.; Qi, Y. Construction land expansion and cultivated land protection in urbanizing China: Insights from national land surveys, 1996-2006. Habitat Int. 2015, 46, 13-22. [CrossRef]

109. Yan, H.M.; Liu, J.Y.; Huang, H.Q.; Tao, B.; Cao, M.K. Assessing the consequence of land use change on agricultural productivity in China. Glob. Planet. Chang. 2009, 67, 13-19. [CrossRef]

110. Liu, L.; Wang, H.-J.; Yue, Q. China's coastal wetlands: Ecological challenges, restoration, and management suggestions. Reg. Stud. Mar. Sci. 2020, 37, 101337. [CrossRef]

111. Sun, J.; Li, Y.P.; Gao, P.P.; Suo, C.; Xia, B.C. Analyzing urban ecosystem variation in the City of Dongguan: A stepwise cluster modeling approach. Environ. Res. 2018, 166, 276-289. [CrossRef]

112. Wang, M.; Peng, J.; Hu, Y.N.; Du, Y.; Qiu, S.; Zhao, M. Scale consistency for investigating urbanization level, vegetation coverage, and their correlation. Urban For. Urban Green. 2021, 59, 126998. [CrossRef]

113. Xu, X.; Liu, H.; Jiao, F.; Gong, H.; Lin, Z. Time-varying trends of vegetation change and their driving forces during 1981-2016 along the silk road economic belt. Catena 2020, 195, 104796. [CrossRef]

114. Li, H.; Ding, J.; Zhang, J.; Yang, Z.; Yang, B.; Zhu, Q.; Peng, C. Effects of Land Cover Changes on Net Primary Productivity in the Terrestrial Ecosystems of China from 2001 to 2012. Land 2020, 9, 480. [CrossRef]

115. Jiang, L.; Liu, Y.; Wu, S.; Yang, C. Analyzing ecological environment change and associated driving factors in China based on NDVI time series data. Ecol. Indic. 2021, 129, 107933. [CrossRef]

116. Liu, H.; Cao, L.; Jia, J.; Gong, H.; Qi, X.; Xu, X. Effects of land use changes on the nonlinear trends of net primary productivity in arid and semiarid areas, China. Land Degrad. Dev. 2021, 32, 2183-2196. [CrossRef]

117. Chang, S.; Wang, J.; Zhang, F.; Niu, L.; Wang, Y. A study of the impacts of urban expansion on vegetation primary productivity levels in the Jing-Jin-Ji region, based on nighttime light data. J. Clean. Prod. 2020, 263, 121490. [CrossRef]

118. Zhang, X.; Yue, Y.; Tong, X.; Wang, K.; Qi, X.; Deng, C.; Brandt, M. Eco-engineering controls vegetation trends in southwest China karst. Sci. Total Environ. 2021, 770, 145160. [CrossRef] [PubMed]

119. Cao, S.; Xia, C.; Yue, H.; Ma, H.; Lin, G. Targeted control measures for ecological restoration in Western Fujian, China. Land Use Policy 2018, 76, 186-192. [CrossRef]

120. Feng, R.; Wang, F.; Wang, K. Spatial-temporal patterns and influencing factors of ecological land degradation-restoration in Guangdong-Hong Kong-Macao Greater Bay Area. Sci. Total Environ. 2021, 794, 148671. [CrossRef]

121. Jiang, C.; Zhang, H.; Zhao, L.; Yang, Z.; Wang, X.; Yang, L.; Wen, M.; Geng, S.; Zeng, Q.; Wang, J. Unfolding the effectiveness of ecological restoration programs in combating land degradation: Achievements, causes, and implications. Sci. Total Environ. 2020, 748, 141552. [CrossRef]

122. Hong, C.; Burney, J.; Pongratz, J.; Nabel, J.; Mueller, N.; Jackson, R.; Davis, S. Global and regional drivers of land-use emissions in 1961-2017. Nature 2021, 589, 554-561. [CrossRef]

123. Frank, D.; Reichstein, M.; Bahn, M.; Frank, D.; Mahecha, M.; Smith, P.; Thonicke, K.; Velde, M.; Vicca, S.; Babst, F.; et al. Effects of climate extremes on the terrestrial carbon cycle: Concepts, processes and potential future impacts. Glob. Chang. Biol. 2015, 21, 2861-2880. [CrossRef] [PubMed]

124. Reeves, M.C.; Moreno, A.L.; Bagne, K.E.; Running, S.W. Estimating climate change effects on net primary production of rangelands in the United States. Clim. Chang. 2014, 126, 429-442. [CrossRef]

125. Wu, S.; Yin, Y.; Zhao, D.; Huang, M.; Shao, X.; Dai, E. Impact of future climate change on terrestrial ecosystems in China. Int. J. Climatol. 2009, 30, 866-873. [CrossRef]

126. He, H.; Shaoqiang, W.; Wang, J.; Xiaoli, R.; Zhou, L.; Piao, S.; Hao, Y.; Weimin, J.; Gu, F.; Yu, S.-Y.; et al. Altered trends in carbon uptake in China's terrestrial ecosystems under the enhanced summer monsoon and warming hiatus. Natl. Sci. Rev. 2019, 6, 505-514. [CrossRef] [PubMed]

127. Jung, M.; Reichstein, M.; Schwalm, C.R.; Huntingford, C.; Sitch, S.; Ahlström, A.; Arneth, A.; Camps-Valls, G.; Ciais, P.; Friedlingstein, P.; et al. Compensatory water effects link yearly global land CO2 sink changes to temperature. Nature 2017, 541, 516-520. [CrossRef] [PubMed] 
128. Yao, Y.; Wang, X.; Li, Y.; Wang, T.; Shen, M.; Du, M.; He, H.; Li, Y.; Luo, W.; Mingguo, M.; et al. Spatiotemporal pattern of gross primary productivity and its covariation with climate in China over the last thirty years. Glob. Chang. Biol. 2017, 24, 184-196. [CrossRef] [PubMed]

129. Zhang, L.; Wang, H.; He, S.; Wei, H.; Li, Y.; Liu, C. A Segmented Polynomial Model to Evaluate Passive Intermodulation Products from Low-Order PIM Measurements. IEEE Microw. Wirel. Compon. Lett. 2019, 29, 14-16. [CrossRef]

130. Friend, A.; Lucht, W.; Rademacher, T.; Keribin, R.; Betts, R.; Cadule, P.; Ciais, P.; Clark, D.; Dankers, R.; Falloon, P.; et al. Carbon residence time dominates uncertainty in terrestrial vegetation responses to future climate and atmospheric $\mathrm{CO}_{2}$. Proc. Natl. Acad. Sci. USA 2013, 111, 3280-3285. [CrossRef]

131. Tian, M.; Row, K.H. SPE of Tanshinones from Salvia miltiorrhiza Bunge by using Imprinted Functionalized Ionic Liquid-Modified Silica. Chromatographia 2011, 73, 25-31. [CrossRef]

132. Liu, X.; Zhang, Y.; Han, W.; Tang, A.; Shen, J.; Cui, Z.; Vitousek, P.; Erisman, J.W.; Goulding, K.; Christie, P.; et al. Enhanced nitrogen deposition over China. Nature 2013, 494, 459-462. [CrossRef] 